University of Nebraska - Lincoln

DigitalCommons@University of Nebraska - Lincoln

Publications, Agencies and Staff of the U.S.

Department of Commerce

U.S. Department of Commerce

2006

\title{
Evaluation of the National Weather Service Operational Hydrologic Model and Forecasts for the American River Basin
}

\author{
Eylon Shamir \\ Hydrologic Research Center \\ Theresa M. Carpenter \\ University of California \\ Peter Fickenscher \\ California-Nevada River Forecast Center \\ Konstantine P. Georgakakos \\ University of California
}

Follow this and additional works at: https://digitalcommons.unl.edu/usdeptcommercepub

Part of the Environmental Sciences Commons

Shamir, Eylon; Carpenter, Theresa M.; Fickenscher, Peter; and Georgakakos, Konstantine P., "Evaluation of the National Weather Service Operational Hydrologic Model and Forecasts for the American River Basin" (2006). Publications, Agencies and Staff of the U.S. Department of Commerce. 51.

https://digitalcommons.unl.edu/usdeptcommercepub/51

This Article is brought to you for free and open access by the U.S. Department of Commerce at DigitalCommons@University of Nebraska - Lincoln. It has been accepted for inclusion in Publications, Agencies and Staff of the U.S. Department of Commerce by an authorized administrator of DigitalCommons@University of Nebraska - Lincoln. 


\title{
Evaluation of the National Weather Service Operational Hydrologic Model and Forecasts for the American River Basin
}

\author{
Eylon Shamir ${ }^{1}$; Theresa M. Carpenter ${ }^{2}$; Peter Fickenscher ${ }^{3}$; and Konstantine P. Georgakakos, M.ASCE ${ }^{4}$
}

\begin{abstract}
This paper evaluates the National Weather Service operational hydrologic model and operational flow forecasts for several subbasins of the American River. The evaluation includes: (1) the quality of the 6-h operational flow forecasts with up to 5 days lead time; (2) the hydrologic model ability to reproduce observed mean daily flows; and (3) the reliability of the ensemble streamflow predictions of the hydrologic model to reproduce extremes of the monthly volume of full natural flow to Folsom Lake. The results indicate that the model represents the observed flow record well for sites and/or flow ranges unaffected by upstream regulation. Real time operational forecast produced by a forecaster that considers model predictions have good skill out to $18 \mathrm{~h}$ with precipitation forecast contributing significantly to forecast uncertainty. Certain high-flow events with a spatially distributed mix of snow/rain over the basin may not be reproduced well by the basic spatially lumped structure of the operational snow-soil-channel model. It is suggested to incorporate upstream regulation rules into the operational models for better reproduction of observed medium and low flows. Routine evaluation based on a national archive of operational flow forecasts and observations is also recommended.
\end{abstract}

DOI: 10.1061/(ASCE)1084-0699(2006)11:5(392)

CE Database subject headings: Streamflow; Predictions; Forecasting; California; River basins.

\section{Introduction}

The present study presents a systematic evaluation of the National Weather Service (NWS) hydrologic forecast model and operational short-term forecasts for the American River basin. In particular, we evaluate: (1) operational short-term flow forecasts; (2) retrospective simulations produced by the model in an operational environment using operational databases; and (3) ensemble predictions of monthly flow extremes produced off-line by the model. Various terms have been used in past studies to characterize such comparisons between hindcast and forecast simulations, and observations (i.e., validation, verification, confirmation,

${ }^{1}$ Post Doctoral Associate, Hydrologic Research Center, 12780 High Bluff Dr., Ste 250, San Diego, CA 92130 (corresponding author). E-mail: eshamir@hrc-lab.org

${ }^{2}$ Hydrologic Engineer, Hydrologic Research Center, 12780 High Bluff Dr., Ste 250, San Diego, CA 92130. Graduate Student, Scripps Institution of Oceanography, Univ. California at San Diego, La Jolla, CA. E-mail: tcarpenter@hrc-lab.org

${ }^{3}$ Hydrologic Forecaster, California-Nevada River Forecast Center, National Weather Service, 3310 El Camino Ave., Sacramento, CA 95821. E-mail: peter.fickenscher@noaa.gov

${ }^{4}$ Director and Senior Research Scientist, Hydrologic Research Center, 12780 High Bluff Dri., Ste 250, San Diego, CA 92130. Adjunct Professor, Scripps Institution of Oceanography, Univ. California at San Diego, La Jolla, CA. E-mail: kgeorgakakos@hrc-lab.org

Note. Discussion open until February 1, 2007. Separate discussions must be submitted for individual papers. To extend the closing date by one month, a written request must be filed with the ASCE Managing Editor. The manuscript for this paper was submitted for review and possible publication on November 9, 2004; approved on January 19, 2006. This paper is part of the Journal of Hydrologic Engineering, Vol. 11, No. 5, September 1, 2006. CASCE, ISSN 1084-0699/2006/5-392-407/ $\$ 25.00$. evaluation, etc. see, e.g., Oreskes et al. 1994). Herein we use the term evaluation consistently for the three case studies mentioned above.

Evaluation of operational hydrometeorological forecasts that are relevant for hydrology has a long history. From the early study of Gentry (1950) pertaining to convective shower forecasting to the landmark study of Murphy and Winkler (1987) that introduced probabilistic verification methods, to the more recent study of Mullen and Buizza (2001) regarding ensemble precipitation forecasts, a variety of evaluation studies have examined the accuracy of short-term precipitation forecasts for a variety of hydroclimatic regimes (e.g., in southern China by Li and Lai 2004; in Europe by Sokol 2003; in Australia by McBride and Ebert 2000; and in the United States by Nutter and Manobianco 1999 and Olson et al. 1995). In addition to short-term operational forecasts, special-purpose and high resolution precipitation forecasts have been evaluated (e.g., summer convection in Case et al. 2002; winter ice storms in Manning and Davis 1997). Finally, evaluations of longer term (e.g., seasonal) operational probabilistic hydrometeorological forecasts has also been done (e.g., Hartman et al. 2002; Wilks 2000).

The aforementioned evaluations are useful for hydrologic forecast applications as precipitation is an important input to hydrologic models and the uncertainty of precipitation forecasts (short and long term) is the most important contributor to the uncertainty of hydrologic forecasts. However, because the soil moisture accounting component filters some of the precipitation uncertainty and there are other sources of uncertainty in the hydrologic model (e.g., parametric and model-structure uncertainty), it is important to directly evaluate flow forecasts produced by operational models using operational-quality data. Direct evaluation of operational flow forecasts has not been reported, although there are several studies that have evaluated simulations produced by operational models (running off line) using operational quality 
data. With respect to flow simulations using operational quality data and models, examples include those associated with the World Meteorological Organization (WMO) hydrologic forecasting intercomparison experiments [e.g., WMO (1975) for spatially lumped conceptual hydrologic models, WMO (1986) for spatially lumped snowmelt runoff models, and WMO (1992) for spatially lumped hydrologic models using real-time updating procedures]. More recently, there are various special-purpose intercomparison model studies [e.g., Smith et al. 2004 for distributed hydrologic model simulations with participation of models of research and operational quality; and Refsgaard and Knudsen (1996) for intercomparing spatially distributed and spatially lumped model simulations].

Longer term statistical or ensemble flow forecasts produced off-line using operational quality models have also been evaluated in some cases. A few recent studies that examined monthly or seasonal forecasts are those of Bradley et al. (2004), Franz et al. (2003), Carpenter and Georgakakos (2001), Uvo and Graham (1998), Georgakakos et al. (1998), Berri and Flamenco (1999), and Piechota et al. (1998).

The present study complements these previous studies by focusing for the first time on the comprehensive evaluation of the NWS operational forecast models and procedures using data from operational databases. The application basin for this evaluation is the American River basin, and the operational flow forecasts/ simulations, models and data were obtained from the California Nevada River Forecast Center (CNRFC) of the U.S. NWS. All the flow forecasts and simulations were produced by CNRFC, except for the ensemble predictions of monthly volumes, which were produced by the authors using the operational models in an ensemble streamflow prediction framework (as described in the corresponding section).

This paper is organized as follows: In the next section pertinent information on Folsom Lake drainage basin including features of its hydrometeorology is provided. In the following section we describe pertinent features of the operational hydrologic forecast procedures and models used by River Forecast Centers (RFC's) in the United States. The methodology and the available data are discussed in the next section. The following three sections present evaluation of: (1) the short-term operational flow forecasts with lead times up to 5 days with 6-h resolution; (2) retrospective historical 6-h flow simulations produced by CNRFC using the operational hydrologic models; and (3) retrospective ensemble monthly flow forecasts produced off line by operational hydrologic models with data from the operational database. Conclusions and recommendations are presented in the last section.

\section{Application Basin}

The application area is the American River drainage basin upstream of Folsom Lake in north-central California (Fig. 1). The American River flows westward from the crest of the Sierra Nevada $(3,200 \mathrm{~m})$ through rugged and thinly vegetated high terrain and, subsequently, through forested and mildly sloping moderate elevations. We focus on the area of the basin that drains into Lake Folsom $\left(4,740 \mathrm{~km}^{2}\right)$, which is located about $40 \mathrm{~km}$ east of Sacramento, Calif. at about $200 \mathrm{~m}$ above sea level. The basin area spans the longitude range $\left(121.2-119.9^{\circ}\right)$ and the latitude range $\left(38.6-39.4^{\circ}\right)$. The regulated Folsom Lake, completed in 1956, mitigates flood damage for approximately 400,000 people and $\$ 37$ billion worth of vulnerable property in the city of Sacramento. Folsom Lake's effectiveness to mitigate flood damage has

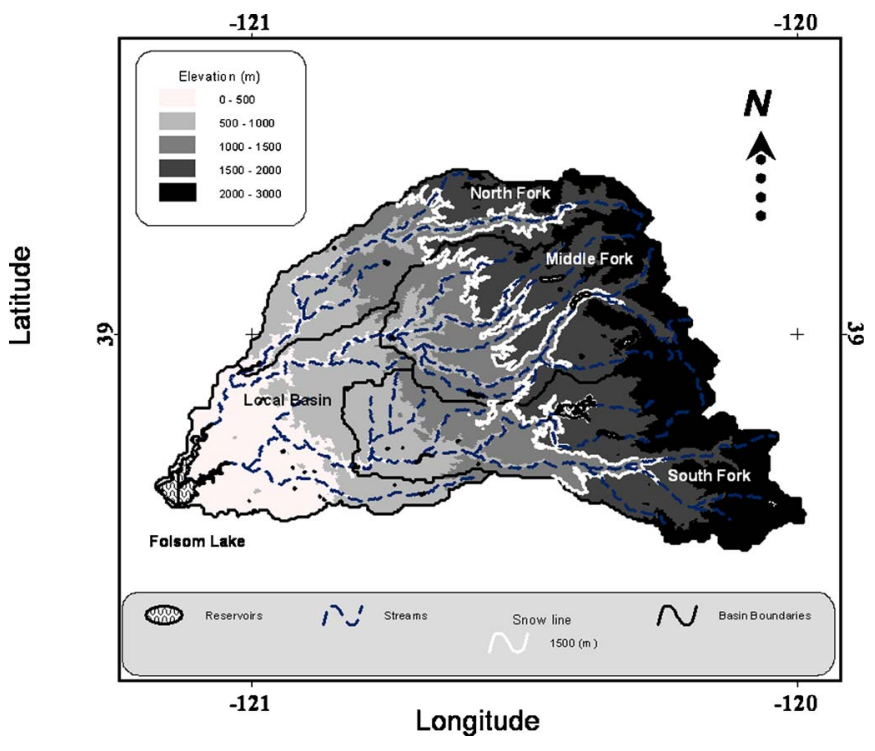

Fig. 1. American River Basin with outlet at Folsom Lake

been the subject of several government reports summarized in NRC (1995).

The climate in this region is Mediterranean; i.e., most precipitation occurs in the winter alternating between rainfall and snowfall, while summers are generally dry and hot. At the higher elevations (typically above $1,500 \mathrm{~m}$ ), snowfall develops an intermittent winter snow pack that melts completely during spring and early summer. The mean areal precipitation exhibits large interannual variability and significant variability in areal distribution with elevation (450-1800 $\mathrm{mm} \mathrm{year}^{-1}$ ). During extreme flow events, daily precipitation rates in excess of $250 \mathrm{~mm} /$ day have been occasionally observed in the upper elevations.

Folsom Lake has a capacity of about $1,200 \times 10^{6} \mathrm{~m}^{3}$ $(\sim 1$ million acre $\mathrm{ft})$. The Lake receives its natural flow from the North, Middle, and South Forks of the American River basin. The North and Middle Forks combine their flows upstream of the lake while the South Fork flows directly into the lake (Fig. 1). The forks flow swiftly through steep rocky canyons. Except in forested areas and in areas overlaid with thick snow pack, rainfall quickly finds its way into the channels and from there into the Lake. The 100-year return period naturalized daily-averaged inflow to Lake Folsom is estimated by the U.S. Corps of Engineers to be in excess of $7,100 \mathrm{~m}^{3} / \mathrm{s}$.

The North Fork maintains natural flow and it drains a relatively unimpaired basin. Both the Middle and the South Forks basins have reservoirs and diversion canals which are regulated and alter natural flow as it is measured by the U.S Geological Survey at each basin's outlet. Approximately $42 \%$ of the drainage area upstream of Folsom Lake is regulated. In addition, there is trans-boundary water transfer from the Middle to the South Fork, which averages approximately $220 \times 10^{6} \mathrm{~m}^{3}$ year $^{-1}$, with a range of $40-440 \times 10^{6} \mathrm{~m}^{3}$ year $^{-1}$. This translates to an average daily transfer of approximately $7 \mathrm{~m}^{3} / \mathrm{s}$.

Table 1 gives information concerning the forks physical properties and streamflow characteristics. The mean daily full natural flow (FNF) of the Folsom Lake inflow was estimated by CNRFC personnel based on water budget analysis that utilizes changes of observed lake levels, observed lake outflow, estimated lake evaporation, and known diversions occurring downstream of the fork gages. It can be seen that; (1) the North Fork basin has the 
Table 1. Physical and Flow Characteristics of American River Forks and Folsom Lake (Water Years of 1965-1989)

\begin{tabular}{|c|c|c|c|c|c|c|c|}
\hline \multirow[b]{2}{*}{ Basins } & \multirow[b]{2}{*}{ Data source } & \multirow[b]{2}{*}{$\begin{array}{l}\text { Basin area } \\
\left(\mathrm{km}^{2}\right)\end{array}$} & \multirow[b]{2}{*}{$\begin{array}{l}\text { Elevation range } \\
(\mathrm{m})\end{array}$} & \multirow[b]{2}{*}{$\begin{array}{l}\text { Mean annual flow } \\
\left(10^{6} \mathrm{~m}^{3} \mathrm{y}^{-1}\right)\end{array}$} & \multicolumn{3}{|c|}{ Mean daily flow $\left(\mathrm{m}^{3} / \mathrm{s}\right)$} \\
\hline & & & & & $90 \%$ & Maximum & $10 \%$ \\
\hline Folsom Lake & $\mathrm{FNF}^{\mathrm{a}}$ & 4,740 & $200-3,000$ & 3,200 & 216 & 4,240 & 21 \\
\hline North Fork & $11,427,000^{\mathrm{b}}$ & 875 & $260-2,630$ & 770 & 58 & 1,300 & 1 \\
\hline Middle Fork & $11,433,300^{\mathrm{b}}$ & 1,245 & $350-3,017$ & 1,071 & 69 & 1,840 & 4 \\
\hline South Fork & $11,444,500^{\mathrm{b}}$ & 1,530 & $419-2,952$ & 1,320 & 93 & 1,190 & 9 \\
\hline
\end{tabular}

${ }^{a}$ Full Natural Flow produced by CNRFC.

${ }^{\mathrm{b}}$ USGS streamflow gage.

smallest area, being barely larger than half the area of the South Fork; and (2) the Middle and South Fork basins include the highest elevations at the basin. Table 1 underlines the highly intermittent occurrence of extreme events within the period of record for which statistics are shown (1965-1989). It also shows that the Folsom Lake capacity to hold water is approximately equal to a third of the mean annual inflow.

Typical discharge hydrographs into the Folsom Lake (water year 1983-1984) and at the fork basin outlets are plotted in Fig. 2. In this figure, the discharge inflow into the Lake is the estimated mean daily FNF, whereas the hydrographs plotted for the forks are the observed flows at the gages (Table 1). To facilitate the visualization of the range of flow regimes, in the lower panel of Fig. 2 the mean daily discharge data are transformed using the Box-Cox transformation (Box and Cox 1964). This transformation maps the discharge values onto a more homoscedastic time series with an approximately normal distribution (Sorooshian and Dracup 1980). The Box-Cox transformation equation used in this work is given by: $q_{t, \text { transform }}=\left[\left(q_{t}+1\right)^{\lambda}-1\right] / \lambda$, where $\lambda$ is set equal to 0.3 .
It can be seen that the effect of regulation on the Middle and South Forks is significant during the summer months. The upstream reservoirs hold water through the winter and release the water gradually in the summer. This is in opposition to the North Fork behavior that shows a rapid decline through the summer months (e.g., compare the flows after the time indicated by the arrow in Fig. 2 which is associated with approximately $42 \mathrm{~m}^{3} / \mathrm{s}$ ). It is interesting to contrast the smooth line appearance of the North Fork flow recessions with the jagged discharge lines of the other fork basin outflows and of the Folsom Lake inflow. The jagged lines, especially those of the Middle Fork outflow and of the Folsom Lake inflow, are probably the result of upstream flow regulation, effected daily according to a given schedule of releases. Over all, the three forks are similar in their hydrologic responses and their relative contribution to the Lake inflow is substantially correlated with their areas (average unit area flows of about $0.87 \mathrm{~m} \mathrm{year}^{-1}$ ).
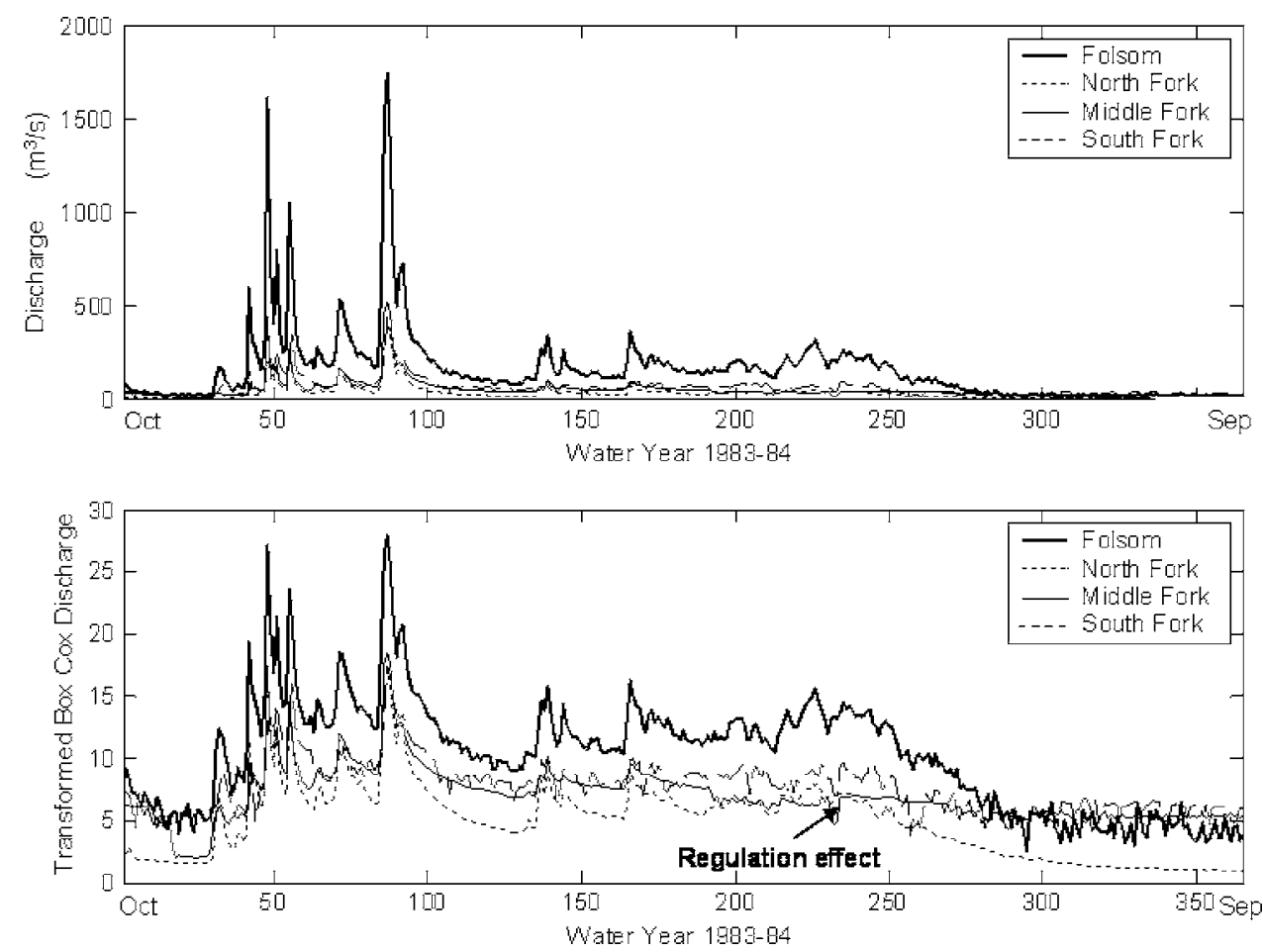

Fig. 2. Typical observed hydrographs from North, Middle, and South Forks and full natural inflow into Folsom Lake during water year 1983-1984 


\section{Operational Forecast Procedures and Models}

The two important functions of the RFCs of the NWS are: (1) to issue river and flood forecasts and warnings for the protection of lives and property; and (2) to provide basic hydrologic forecast information for the nation's environmental and economic wellbeing. In practice, both functions require implementation of a river forecast system that continuously predicts the river flow conditions with various lead times.

At the CNRFC these forecasts are made using the NWS River Forecast System (NWSRFS), which is a system of hydrologic and hydraulic models and procedures that provides streamflow predictions at points of interest. The implementation of the hydrologic models within the NWSRFS includes two model uses. The first use is for short forecast lead times (i.e., up to 5 days time with a 6-h resolution) mainly in support of flood watches and warnings. The second use is for longer forecast lead times (i.e., weekly, monthly, seasonal, and annual flow volumes with daily resolution) and pertains mainly to water resources and riverine ecosystem management.

The NWSRFS hydrologic models have been used in several recent studies in a nonoperational environment. These studies include coupled forecast and management of large reservoirs (Georgakakos et al. 1998), long-term predictions of flow associated with climate change (Lettenmaier and Gan 1990), and long-term streamflow prediction (monthly and annual) of streamflow water yield (e.g., Lohmann et al. 2003).

During the winter months (November-April), the CNRFC generates daily short-term flow forecasts by forcing the hydrologic models with 5-day precipitation and surface air temperature forecasts with 6-h resolution, and then integrating the models forward starting from current model states initial conditions (i.e., snow pack properties, soil moisture, and channel water contents). As model forcing and streamflow observations become available, the model states are updated either manually by the operational forecasters using ad hoc procedures or automatically using statespace formulations and real-time state estimators (Sperfslage and Georgakakos 1996).

During the water supply season (January-July) the CNRFC regularly generates longer-term ensemble forecasts that predict seasonal water information, which includes the timing and the magnitude of the peak flow resulting from snow melt. For these forecasts, the ensemble streamflow prediction (ESP) procedure of the NWS is used (Day 1985; Smith et al. 1991). The ESP is a probabilistic forecast procedure, which drives the hydrologic snow-soil-channel models in turn by historical observations of precipitation and temperature from the same historical calendar date (month and day) as the date of the forecast preparation time. The hydrologic model then generates likely future streamflow time series using current basin conditions as initial model conditions. Use of all available pairs of precipitation and temperature time series results in a collection (ensemble) of equally likely future simulated streamflow time series. The ensemble of the generated streamflow time series may be used to produce probabilistic forecasts for various user-defined future flow events (e.g., high or low volumes within a certain period, etc.)

For both short-term and long-term operational streamflow forecasts the hydrologic component of the NWSRFS is used with the same preset hydrologic model configuration (i.e., same model, parameters, and state variables, with the latter evolving in 6-h time steps). In the operational setup, the operational hydrologists are able to intervene during the model prediction phase. This intervention is based on professional judgment and experience with the model and the application basins. The forecaster intervention can be done by modifying parameter values, updating the state variables or modifying the input variables. For example during the snow season, the operational hydrologist can modify the melt factor parameter to better control the melting rate of the snow pack, update the state variables of the snow using monthly snow courses surveys, and correct the mean areal precipitation (MAP) and the mean areal temperature (MAT). It is important to clarify that the evaluation of operational forecasts is the evaluation of a hybrid product that includes model skill and hydrologist/ forecaster added value. Therefore, we cannot use the forecasts alone to evaluate the model.

Although the operational forecasts are a hybrid of model output and professional judgment and such forecasts need be evaluated directly, model evaluation should also include the examination of the model ability to predict the hydrographs without persistent intervention and updating of the states. This is particularly so for longer-term forecast applications (such as ESP) in which the model is essentially used in simulation mode. Therefore, it is reasonable to evaluate the performance of the hydrologic model with respect to meeting intended objectives through a retrospective study that uses continuous historical observations from operational databases and a preset model configuration and parameters. Such model evaluation is simpler for regions such as California that have consistently long dry seasons that reduce interannual dependency. Finally, the evaluation of the reliability of the longer-term ensemble flow forecasts is paramount to their effective use for water resources management (e.g., Georgakakos et al. 1998; Yao and Georgakakos 2001).

The operational hydrologic model used to produce the operational short- and long-term forecasts consists of the Sacramento soil moisture accounting model (SAC-SMA) (Burnash et al. 1973) to simulate runoff production, the SNOW-17 model (Anderson 1973) to simulate snow melt and snow water equivalent, and a routing scheme that conveys runoff to the location of interest. Unit hydrograph procedures are used to route the flows for simulations of the operational model with historical data, while the cascade of linear conceptual reservoirs of Georgakakos and Bras (1982) is used to route the flows for the real-time shortterm flow forecasts and for the ensemble streamflow forecasts. The hydrologic model consists of time-continuous components that simulate the evolution of the state variables that represent the natural system (e.g., snow mass and energy properties, and soil and channel water contents) at a single time step.

The snow model component is forced by mean areal temperature and precipitation. The mean areal temperature serves as an index for energy exchange across the snow-air interface and is used to compute snow melt heat exchange and to determine snowfall from rain. During periods with no rain, temperature is used as a melt index with a seasonally varied melt factor. For rain on snow events, a simplified energy balance approach that considers temperature and precipitation data are used. The model also accounts for snow-soil interface interaction, and the liquid storage of the pack, together with delay and attenuation due to liquid transmission through the snow pack.

The SAC-SMA is a continuous model of the wetting and drying processes in the soil. It simulates changes in the water content of upper and lower soil zones and in conceptual storages of tension (water that can only be depleted by evapotranspiration) and free (gravitational) water. The model is forced by snow melt and/or precipitation and reference potential evapotranspiration, and produces as output runoff from impervious and pervious areas, soil water content, and actual evapotranspiration. The per- 
vious area runoff consists of surface and subsurface runoff, with surface runoff generation depending on both the saturation levels of the soils and the soils ability to percolate water to deeper layers. A variable impervious area model function allows for the increase and decrease of the saturated soil area near the streams. The discrete-time form of the model is described in Burnash et al. (1973), while a continuous-time form is in Georgakakos (1986).

Model parameters consist of 13 SAC-SMA parameters, 7 SNOW-17 parameters, and the unit hydrograph coordinates or the two parameters of the kinematic channel routing model. Estimation of the values of these parameters for specific drainage basins is performed by the RFCs following an interactive calibration methodology that recognizes explicitly the function of the physical/conceptual components of the models (e.g., see NWS 1999b; Koren et al. 2000; Smith et al. 2003; Shamir et al. 2005, regarding SAC-SMA; and Anderson 1973, regarding snow model parameter estimations).

\section{Methodology and Data}

In measured natural systems model performance analysis may be based on the analysis of the prediction or simulation error

$$
\delta_{i}=y_{i}-\hat{y}_{i}
$$

where $y=$ observed value; $\hat{y}=$ corresponding model prediction or simulation; and $\delta=$ prediction error (i.e., residual). The equation is valid for $i=1,2,3, \ldots, n$, where $i$ represents discrete time steps. It is common practice to evaluate the model performance by characterizing the distribution of the residuals. The residual term aggregates many sources of prediction uncertainty that can be related to the model structure and parameters, and to the observed data. In addition, evaluating the residuals from a statistical distribution perspective often reveals: strong temporal dependence, seasonality, annual trends and non-normal distributions with magnitude-dependent variance (e.g., Sorooshian and Dracup 1980; Şen et al. 2003).

In addition to residual performance analysis, the operational calibration and evaluation procedures consider multiple criteria in conjunction with visual examination of the observed and simulated hydrographs and the state variables time series. The NWS operational model calibration procedure uses criteria which accommodate the objectives of the model, examine the peak flow events (time and magnitude) as well as various measures of the daily, monthly, and annual time scale performance.

A commonly used procedure for model evaluation in the hydrologic literature is the split sample approach in which a given data set (e.g., streamflow time series) is divided into a calibration and an independent evaluation subset. Few studies have been conducted to identify the data length required for stable parameter estimates (e.g., Yapo et al. 1996 for rainfall-runoff models; Xia et al. 2004 for land surface models), and their conclusions depend on the performance criteria used. For model and parameter identification it is obvious that the longer the data set, the more details of the basin hydrologic response are considered with attendant benefits to model predictability. For example, if the variability in the calibration data set is smaller than that of the evaluation set (e.g., the driest or wettest year on record are found in the evaluation data set) a calibrated model may have difficulty predicting the evaluation period extremes. To avoid such situations, cross evaluation approaches are developed that repeat the calibrationevaluation procedure by using the evaluation period data to calibrate the model and the calibration period data to evaluate it. For operational purposes it is not uncommon to also use the entire record to produce updated parameter estimates and perform the evaluation after a new dataset has been formed. In this study to adhere to operational practices we conduct the evaluation with a variety of measures which were not considered during the calibration process.

For the evaluation of short-term operational flow forecasts, we use a variety of quadratic error and mean value criteria to examine the performance of the model at various lead times up to a maximum lead time of 5 days with 6 -h resolution. The temporal correlation between forecasts of different forecast lead times is also analyzed. For the historical operational model simulations we use a variety of model performance criteria (e.g., flow residual distributional characteristics, bias measures, quadratic error measures, hydrograph characteristics, etc.) that quantify model performance in different time scales. Several of the criteria used are different from those used by CNRFC for model calibration. In this case and in addition to the flow simulation performance, we also examine the model snow component simulation performance with available snow pillow data. Finally, for the case of ensemble streamflow predictions produced off line using the operational models, the scalar Brier and Skill scores and reliability diagrams are used to evaluate performance with respect to reliability, resolution and sharpness of the ensemble predictions.

The modeling scheme of the operational model that produced the forecasts, simulations and ensemble predictions includes four sub-basins [North, Middle and South Forks and Folsom Local (Fig. 1)]. This scheme is currently under revision by CNRFC personnel mainly in order to better account for the effect of upstream regulation on the South and Middle Fork flows. The first three basins (the forks) were further divided into upper and lower basins using an elevation cutoff of 1,524 $\mathrm{m}(5,000 \mathrm{ft})$. The runoff volumes simulated for the upper and the lower sub-basins were combined (weighted by the sub-basin area), and the combined volume was routed to the sub-basin outlet using a 6-h unit hydrograph procedure specified for each gage location (Table 1) or, as in the case of the short-term flow forecasts or the ensemble flow forecasts, the equivalent linear kinematic channel routing model. The output from the sub-basin outlet is combined with the local flow of the Folsom Local sub-basin, and the combined flow is then routed to the inflow point of Folsom Lake. For each fork gage site and at the Folsom Lake inflow point, the model predicts or simulates the FNF (i.e., full natural flow which is the flow that would occur given no upstream regulation and impairment).

For each of the seven sub-basins (upper and lower areas of each of three forks and the Folsom Local) 6-h MAP and MAT were estimated based on standard operational interpolation procedures from gauge data within and in the proximity of the subbasins (NWS 1999a). It must be noted upfront, that in this study we assume data of good quality and we ignore uncertainty issues pertaining to data quality and data interpolation. Therefore, the errors and uncertainties reported herein are assumed to be solely related to the model structure and parameters. A discussion on the spatiotemporal structure of the MAP errors produced by interpolating data from operational precipitation gages in this mountainous region is in Tsintikidis et al. (2002).

For the period April 1998-January 2003 (four and a half wet seasons), there is a set of archived operational 6-h flow forecasts and associated observations available for the Folsom Basin. These data consist of snapshots of the operational data at each forecast preparation time during this historical period. Each snapshot contains observations (for a historical window ending at the forecast preparation time) and forecasts of discharge for each of the three 
Table 2. Events Used in Analysis of Operational Flow Forecast

\begin{tabular}{|c|c|c|c|c|}
\hline ID number & Event & $\begin{array}{l}\text { Peak MAP } \\
(\mathrm{mm} / 6 \mathrm{hr})\end{array}$ & $\begin{array}{c}\text { Peak flow } \\
\left(\mathrm{m}^{3} / \mathrm{s}\right)\end{array}$ & Flow forecast period \\
\hline 1 & May 1-2, 1998 & 12.6 & 359 & April 27-May 4 \\
\hline 2 & May 25, 1998 & 13.3 & 304 & May 21-27 \\
\hline 3 & May 28, 1998 & 13.3 & 233 & May 24-29 \\
\hline 4 & November 27-23, 1998 & 15.8 & 121 & November 19-24 \\
\hline 5 & November 27-30, 1998 & 14.5 & 180 & November 26-December 1 \\
\hline 6 & December 3, 1998 & 9.8 & 213 & November 29-December 4 \\
\hline 7 & January 15-20, 1999 & 16.8 & 572 & January $13-21$ \\
\hline 8 & January 23, 1999 & 11.1 & 521 & January $18-24$ \\
\hline 9 & February 7-9, 1999 & 15.4 & 1,132 & February $3-10$ \\
\hline 10 & February 16, 1999 & 19.8 & 493 & February $12-19$ \\
\hline 11 & February 20, 1999 & 8.4 & 327 & February $16-21$ \\
\hline 12 & February 28-March 3, 1999 & 19.8 & 397 & February 24-March 4 \\
\hline 13 & January $17-19,2000$ & 15.1 & 246 & January $14-20$ \\
\hline 14 & December 23-24, 2000 & 24.9 & 752 & January $20-25$ \\
\hline 15 & February $10-14,2000$ & 19.6 & 1,038 & February $8-15$ \\
\hline 16 & February 22,2000 & 9.7 & 266 & February $18-24$ \\
\hline 17 & February 26-27, 2000 & 17.9 & 505 & February $23-28$ \\
\hline 18 & May 7-8, 2000 & 17.0 & 310 & May 4-9 \\
\hline 19 & January 2, 2002 & 12.5 & 229 & January $1-3$ \\
\hline 20 & February 19-20, 2002 & 14.2 & 243 & February $15-21$ \\
\hline 21 & March 6-7, 2002 & 16.0 & 288 & March 2-9 \\
\hline 22 & November 7-10, 2002 & 33.7 & 144 & November 4-11 \\
\hline 23 & December 13-17, 2002 & 27.5 & 276 & December 9-17 \\
\hline 24 & December 26-31, 2002 & 8.0 & 149 & December 23-January 1 \\
\hline 25 & January 21-23, 2003 & 7.1 & 182 & January 19-25 \\
\hline
\end{tabular}

forks (Table 1 and Fig. 1). The forecasts included in this record are typically issued at least once per day with maximum forecast lead time of up to 5 days. The dataset provides the basis for a statistical analysis of the forecast errors for various forecast lead times up to $120 \mathrm{~h}$ ( 5 days) and for the three forks and the total basin using selected events during the short historical record.

A total of 25 events (Table 2) were selected based on two general criteria: (1) mean areal precipitation of $10 \mathrm{~mm} / 6 \mathrm{~h}$ or greater for at least one sub-basin, and (2) increase in discharge of $50 \mathrm{~m}^{3} / \mathrm{s}$ or greater associated with a precipitation event on at least the North Fork of the American River. Table 2 also lists the event-maximum MAP computed as an area-weighted average of the individual MAP values of the three forks, and the peak combined flow of the three forks for each event. The values of the maximum MAP range from 7.1 to $33.7 \mathrm{~mm} / 6 \mathrm{~h}$, while the values of the event peak flow range from 121 to $1,132 \mathrm{~m}^{3} / \mathrm{s}$. The analysis involved events with single and with multiple flow peaks. The magnitudes of the events available during the historical period may be classified as medium to low flow events.

For the second model evaluation effort, the evaluation of the historical simulation of the operational model was done with daily data from the period 1965-1989 provided by CNRFC for each of the fork gaged sites and for the Folsom Lake inflow as estimated FNF. Both model simulations and observed data were provided. For the third evaluation effort and for the period 1958-1990, the writers produced ensemble streamflow predictions of monthly duration on the first day of each month of record using the operational hydrologic model and operational daily data. The evaluation of the ensemble streamflow predictions was done for monthly aggregated flow volumes.

\section{Operational Short-Term Flow Forecasts}

For each event of Table 2, a forecast period around the event was identified as beginning approximately 5 days prior to the event peak and continuing through the recession following the peak flow. All unique forecasts issued during the forecast period were considered. The statistical analysis of the discharge forecasts includes the computation of first and second-moment statistics of observations and forecast errors for each sub-basin (North, Middle, and South Forks) and the combined flow for forecast lead-times of 6-h resolution up to 5 days. The analysis also examined the serial correlation of operational forecast errors (i.e., observation-forecast) of given forecast lead times with those of subsequent lead times.

The panels of Fig. 3 present the 25-event average and standard deviation of discharge observations and of discharge forecast errors for various forecast lead times to a maximum of 5 days for the three forks. The corresponding absolute error and percent bias in forecast flows are presented in the panels of Fig. 4. The sample for each forecast lead time includes about 500 values (i.e., 25 events and about 20 forecasts during 5 days). The cyclic appearance in average and standard deviation observations is because of the use of different averaging periods for each forecast lead time and because the selected events include one or two significant events that occur preferentially in the afternoon and night hours. It is interesting to note that for the South Fork the two moments of the flow errors are weakly dependent on forecast lead time. On the other hand, in the North and Middle Forks the average flow error has larger variation and the variance is increasing with lead 

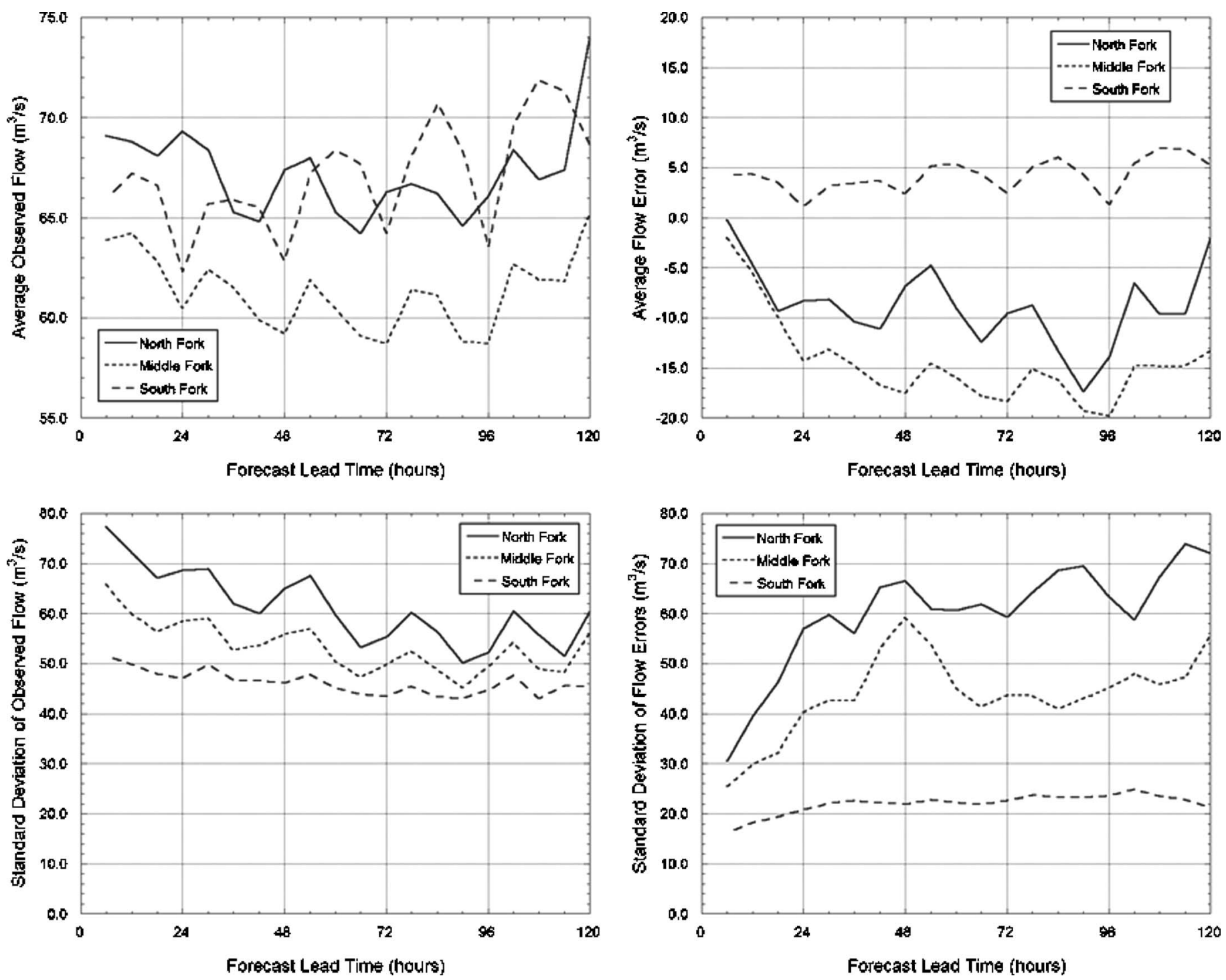

Fig. 3. Statistics of discharge observations and operational forecast errors for various forecast lead times to maximum of 5 days. Panels show: observed mean (upper left); mean error (upper right); standard deviation of observations (lower left); and standard deviation of forecast errors (lower right)

time. This difference may be attributed to lower precipitation rates over the South Fork basin, the presence of flow regulation for medium to low flows in that basin, and the ability of the forecaster to account for such regulation.

The Middle and North Forks show consistent negative bias for all forecast lead times, thus indicating an overestimation in discharge forecasts for the selected periods. This overestimation is on the order of $10-30 \%$ of the average observed flow (right panel Fig. 4). The South Fork shows smaller average errors that are less than $10 \%$ of the average observed flow. The variance in forecast errors for the South Fork is also quite low compared to that of the other sub-basins, and to that of the South Fork observed flows. The variance for the Middle and North Forks approaches the variance of their respective observations after a lead time of approximately $48 \mathrm{~h}$. The behavior of the forecast error statistics during the longer forecast lead times may be influenced by fewer forecasts issued for these longer lead times.

Fig. 5 presents statistics for the combined flow of the three forks. This combined flow constitutes the largest component of the Lake Folsom inflow, with the other and smaller component being the ungauged contribution of the local lake sub-basin. The upper left panel shows the mean combined observed flow (solid line with open circles), mean forecast error (solid line), observed flow standard deviation (dashed line with open circles), standard deviation of flow forecast errors (dashed line), and absolute forecast flow error (dotted line). The upper right panel presents the percent bias of the mean flow error and percent variance explained. In all panels, the statistics are presented for forecast lead times of up to 5 days. The mean flow error is generally negative for all forecast lead times (with the exception of the 6-h forecast lead time), again indicating an overestimation in the combined flow. This overestimation is between 10 and $20 \%$ of the mean combined flow. The variance of the forecast errors approaches the variance of the observed flow at a forecast lead time of $48 \mathrm{~h}$. It is also shown that although the forecast bias magnitude is slowly increasing with forecast lead time the percent of the observations variance explained by the forecast declines sharply with forecast lead time, being $90 \%$ for a 6 -h lead time, $60 \%$ for a $24-\mathrm{h}$ lead time, and less than $30 \%$ for a lead time of $48 \mathrm{~h}$ or greater.

Analysis of the serial correlation among flow forecast errors 

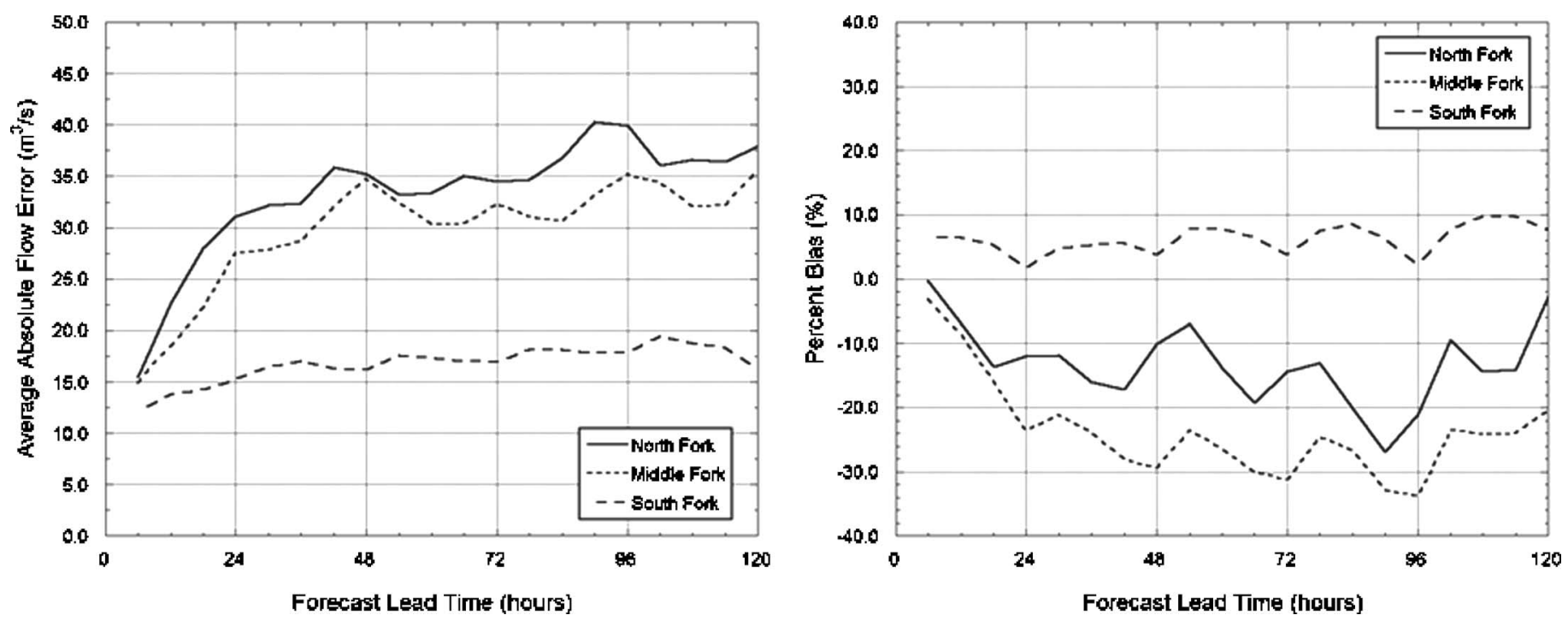

Fig. 4. Average absolute error (left panel) and percent bias (right panel) in operational flow forecasts for various forecast lead times.

was also performed. The serial correlation measures the correlation in errors between one forecast lead time and another. The serial correlation was computed for each forecast lead time with subsequent lead times up to the maximum of $120 \mathrm{~h}$. Fig. 6 presents the serial correlation of forecast flow errors for the 6-h forecast lead time with subsequent lead times for each fork and for the combined flows of the three forks. Forecast lead times up to $72 \mathrm{~h}$ are shown for plot clarity. For forecast lead times up to $72 \mathrm{~h}$, the correlation in flow forecast errors for the 6-h forecast lead time approaches a constant level of $0.2 \pm 0.1$. Generally, it appears that the fastest reduction in the correlation in forecast errors occurs for the Middle Fork and the correlation remains highest for subsequent lead times for the South Fork (likely due to upstream regulation effects not reflected by the forecasts).

\section{Hydrologic Model Simulations}

In this section the model is evaluated retrospectively using a single deterministic simulation run generated from historical

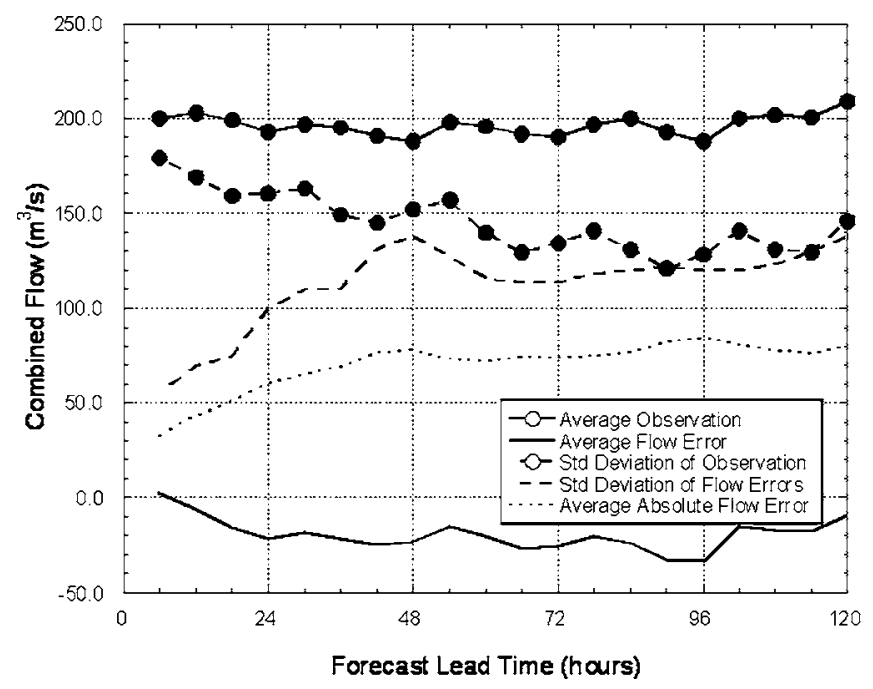

gauge-based reconstructed MAT and MAP time series. This analysis is equivalent to a scenario of a model that runs with no real-time inspection or quality control. As mentioned in the introduction, in the operational setup the states are updated with observation and some parameters can be modified. Therefore, the current evaluation study concerns the quality of the model structure and parameter values. The model simulations were evaluated using short and long time averages. The model performance was examined by comparing the simulated hydrographs to the corresponding observed hydrographs of the three forks and to the estimated FNF to Folsom Lake.

\section{Long-Term Evaluation}

To evaluate the general model performance for the American River, a 25-years (water years 1965-1989) simulation with a 6-h resolution was used to obtain a time series of simulated mean daily flows that correspond to the observed mean daily flow time series at the sub-basin outlets. Evaluating the consistent performance of the model in different flow regimes, the Box-Cox trans-

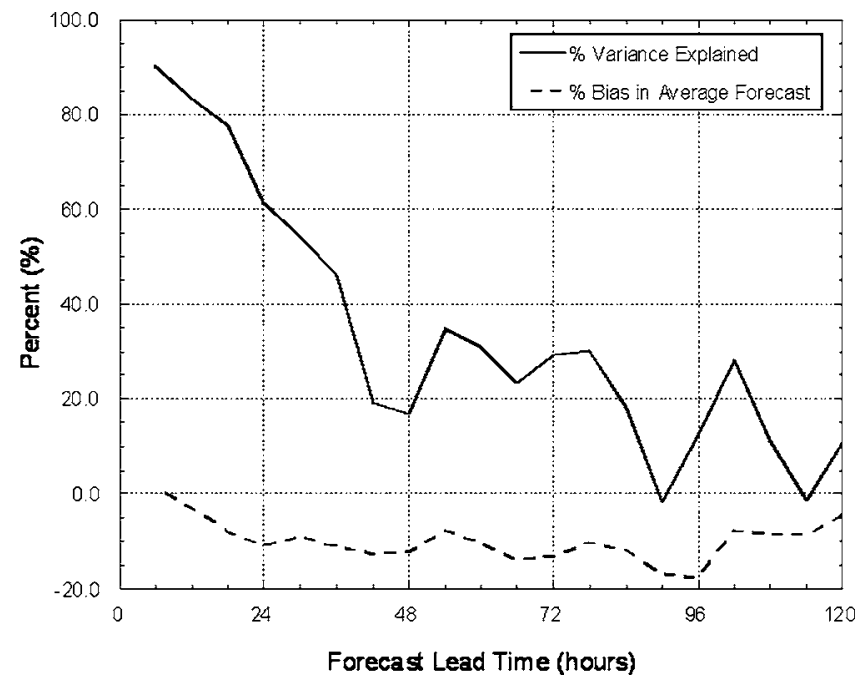

Fig. 5. Statistics of discharge observations and operational forecast errors for combined flows of three forks of American River 


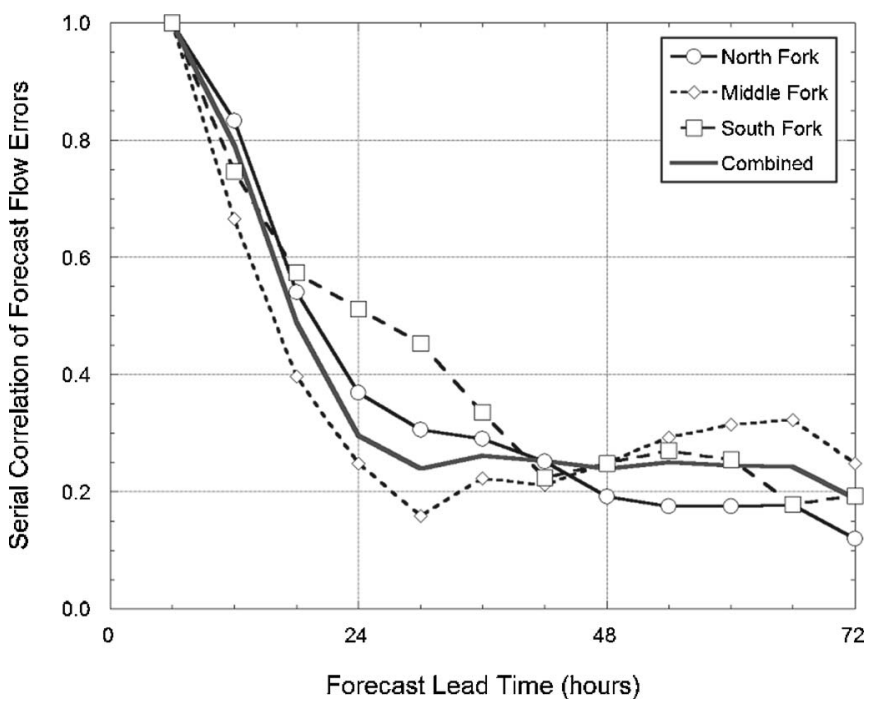

Fig. 6. Serial correlation of operational forecast flow errors for 6-h forecast lead time with subsequent lead times up to $72 \mathrm{~h}$ for all forks and basin combined flow

formed duration curves for the basin, and the three sub-basins are plotted in Fig. 7. Both the Middle and the South Fork simulations consistently underestimate the observed low flow for flow values that are below the flows with a $40 \%$ exceedance. On the other hand, the Middle Fork simulations consistently overestimate the high flow events (higher flows than those with a $40 \%$ exceedance). The underestimation of the low flow is due to the upstream reservoirs that hold water through the wet period of the year and release it during the dry periods as low flow. The overestimation of higher flows on the Middle Fork may be attributed to model inadequacies (i.e., parameters or structure), the trans-boundary transfer of water, and the basin's larger reservoir capacity.

The best performance by far is seen for the discharge simulation at the North Fork, which shows an excellent agreement between simulated and observed flows for the entire flow range. The
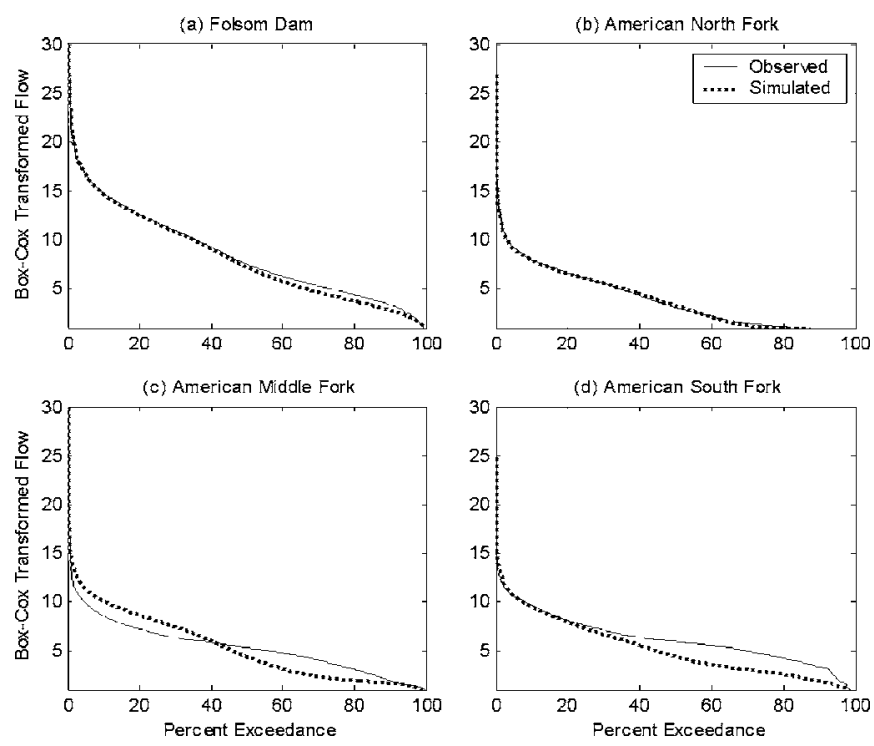

Fig. 7. Observed and simulated (solid and dashed lines, respectively) Box-Cox transformed duration curves of North, Middle, and South Fork outflows and of Folsom Lake full natural inflow simulated flow into the lake, which is the combination of the flows from the three forks and the flow of the local basin adjacent to the Folsom Lake, appears to have good agreement with the estimated FNF except from a consistent but small underestimation of the low flow values (with a higher than $50 \%$ exceedance). Historical FNF calculations are based in part on current water resources demand from surrounding communities, which must be estimated. The consistent underestimation of flow volume in the past points to an ever increasing demand upon Lake Folsom water resources.

To evaluate the ability of the model to provide long term volumetric water outlooks, we plotted the water year volumetric yield for the lake's inflow and flows at the three forks (Fig. 8). The simulated annual volume to the lake is slightly underestimated in 21 years out of the 25 . The mean annual underestimation is about $5 \%$ a year which can be translated to $100 \times 10^{6} \mathrm{~m}^{3}$ year $^{-1}$ (about 80,000 acre $\mathrm{ft} /$ year) or less than a tenth of the Folsom Lake capacity. The annual yields of the forks indicate that the Middle and South Fork are over and underestimating the annual volume, respectively. The average over and underestimation is about 200 $\times 10^{6} \mathrm{~m}^{3}$ year $^{-1}$, which is consistent with the transboundary water transfer volume discussed in the second section. The North Fork is over predicting the volume on average by about 20 $\times 10^{6} \mathrm{~m}^{3}$ year $^{-1}$ (about 7\%). Although the local sub-basin adjacent to Folsom Lake does not have observations, its contribution to the annual flow can be estimated from the difference of the lake discharge and the observation at the forks. A comparison of this difference to the simulated output of the Local Folsom, reveals annual volume under-estimation of about $140 \times 10^{6} \mathrm{~m}^{3} \mathrm{year}^{-1}$, which is within the magnitude of the standard deviation of the lake discharge simulation.

The American River basin has a distinctive seasonal cycle that is reflected in the streamflow. It has a rapid transition in flow from the late summer baseflow-dominated low flow to the winter midrange flows with occasional large flood events, to the spring peak flows dominated by snow melt. This is governed by complex basin dynamics highly dependent on the accretion and melting of the intermittent winter snow pack. To plausibly simulate the flow and account for these seasonal transitions, the model must perform well throughout the year to maintain state variables that capture the system conditions (e.g., snow and soil variables). The nature of this intra annual flow variability can be captured by monthly flow analysis. To evaluate the performance of the operational hydrologic model in the American River basin, the average monthly flow, expressed as a fraction of the annual flow, is plotted with the associated standard deviation in Fig. 9 for the observations and simulations.

Fig. 9 shows that in general the model reproduces well the basin's hydrological response reasonably well. Fig. 9 also shows first that the North Fork simulation captures the observed annual cycle well. Simulations for the Middle and South Forks are overestimating observations during the wet part of the year and underestimating observations during the dry part of the year. The effect of regulation and associated releases contributes to this behavior at the Middle and South Forks. The simulated annual cycle represents well the FNF estimates of the Folsom Lake inflow.

\section{Short-Term Evaluation}

Most flood events in the American River basin are the results of exceptional wintertime rain events. When relatively warm precipitation falls either on saturated ground and runs off as overland flow, or on existing snow pack resulting in rapid snow melt, a 


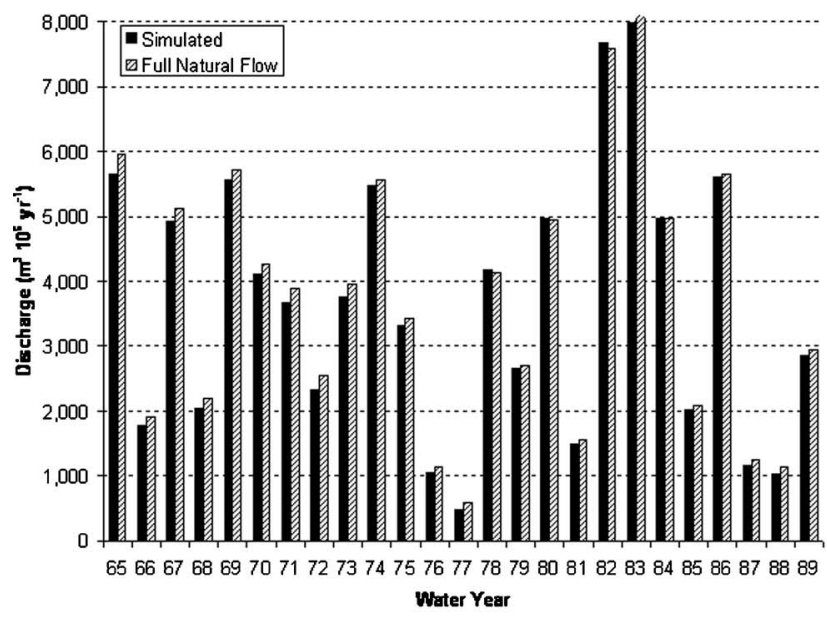

Observed and Simulated Annual Yield in the Middle Fork

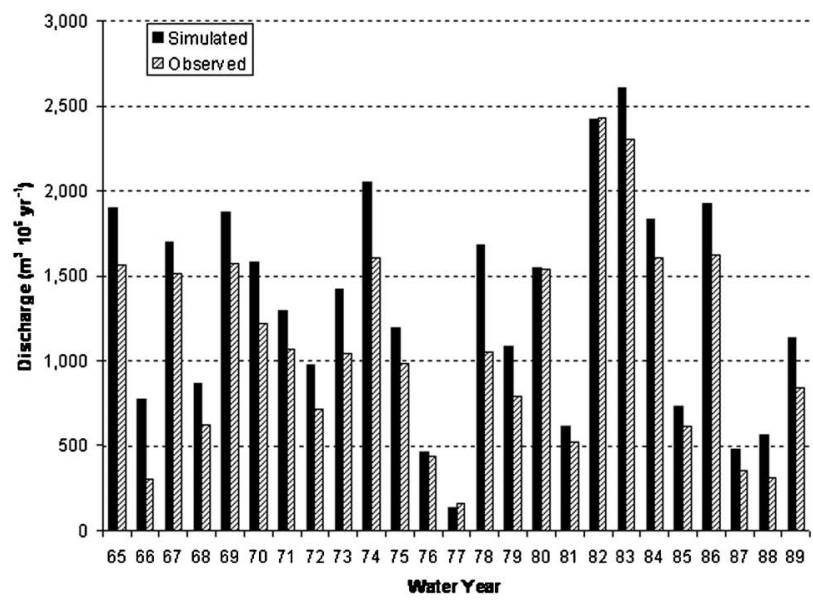

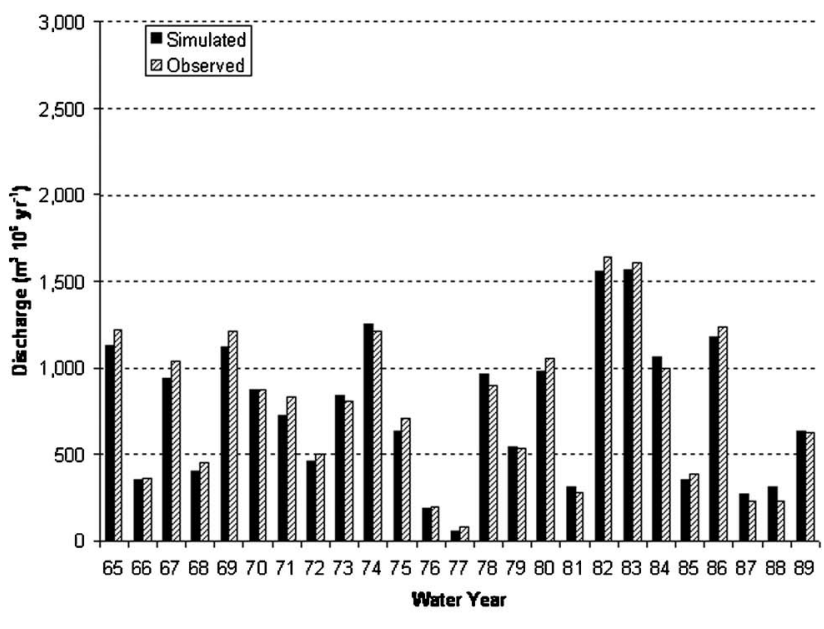

Observed and Sim ulated Annual Yield in the South Fork

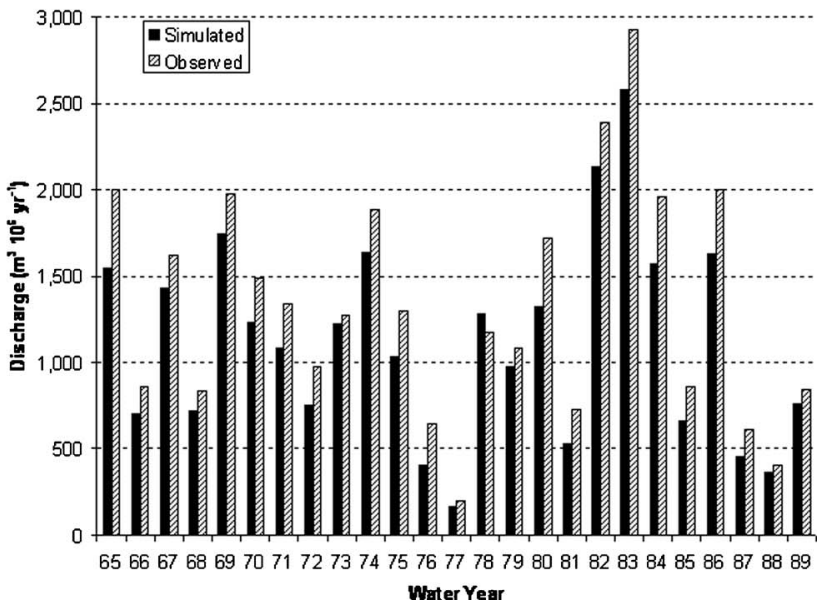

Fig. 8. Simulated and observed annual yields of American River Fork outflows and of Folsom Lake inflow for each year of record
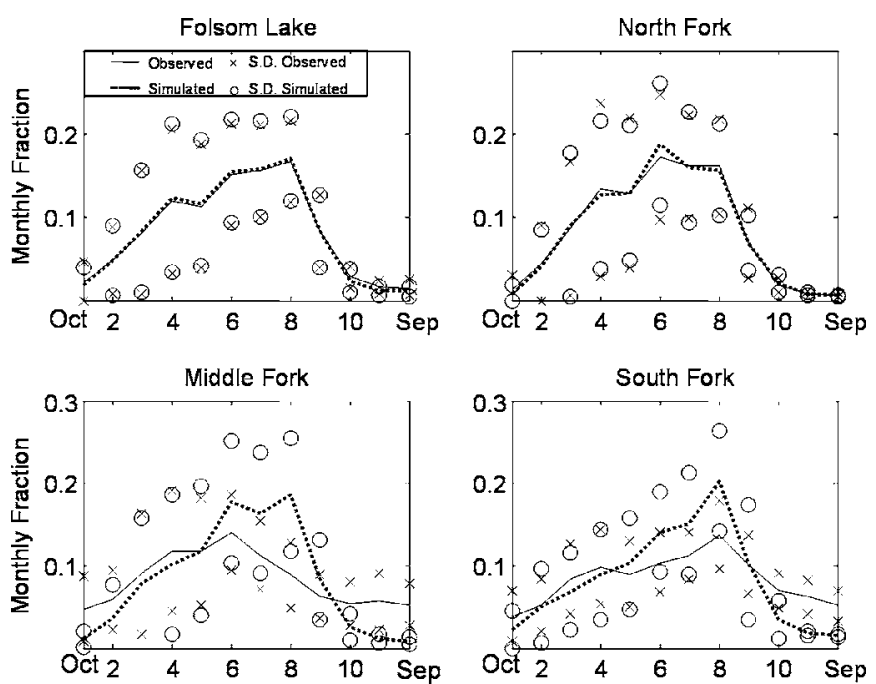

Fig. 9. Observed and simulated (solid and dashed lines, respectively) mean discharge as monthly fraction of year for American River Fork outflows and for Folsom Lake inflow. Standard deviation bounds are shown by symbols $(\times$ for observed and $\bigcirc$ for simulated) (a) Folsom Dam

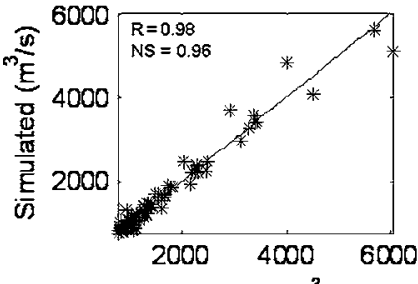

Observed $\left(\mathrm{m}^{3} / \mathrm{s}\right)$

(c) American Mddle Fork

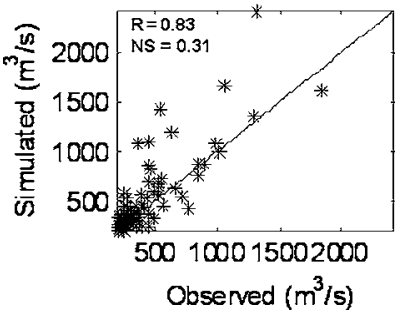

(b) American North Fork

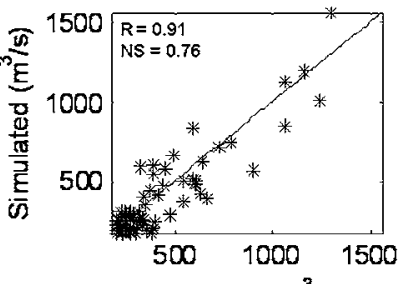

Observed $\left(\mathrm{m}^{3} / \mathrm{s}\right)$

(d) American South Fork

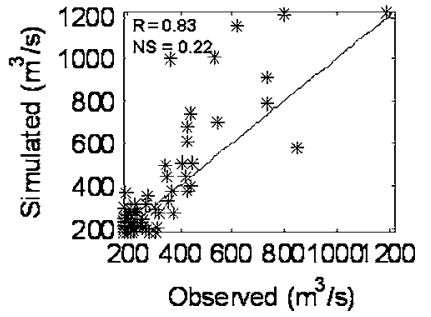

Fig. 10. 1\% highest mean daily flow events during 1965-1989: Observations and simulations of outflows for three forks and of full natural inflow to lake. Correlation $(R)$ and Nash-Sutcliffe efficiency (NS) coefficients are indicated 

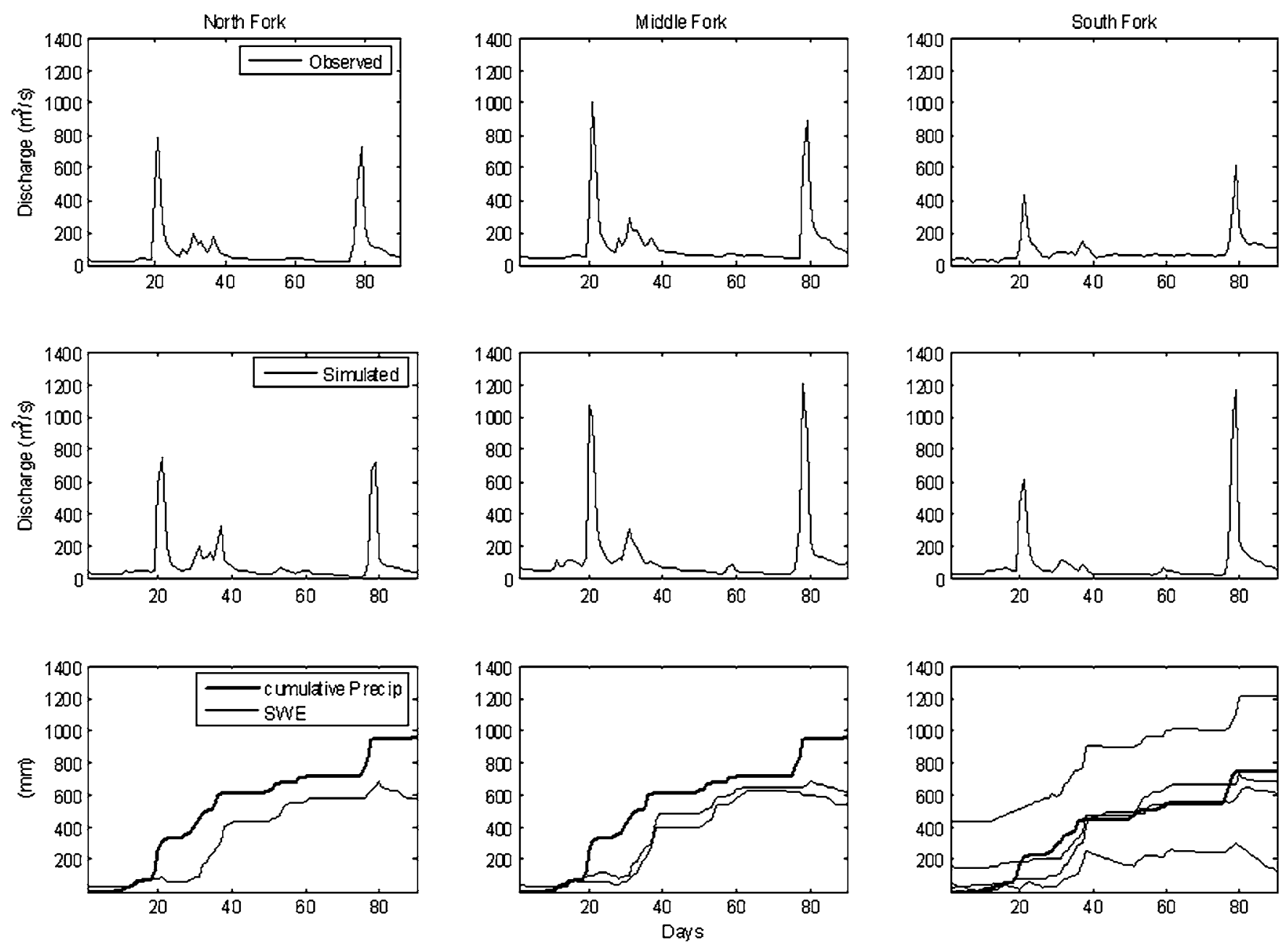

Fig. 11. Observed (upper panels) and simulated (middle panels) hydrographs for December 1981 and February 1982 floods at American River Forks (upper panels). Cumulative precipitation and snow water equivalent (SWE) from multiple snow sensors for corresponding times is shown in lower panels

high flow event occurs. The flow within the Folsom Lake drainage during these events is less dominated by upstream regulation, and simulation of the natural system during these periods should correspond well with the gauge observations.

To evaluate model performance for these high events, in Fig. 10 the $1 \%$ highest daily flow observed during $1965-1989$ is plotted against the corresponding simulated flow for the three forks and the lake FNF (correlation coefficient greater than 0.8 and Nash-Sutcliffe efficiency coefficient are greater than 0.22 , in all cases). It is noted that the Folsom Lake has a flood storage capacity that can accommodate approximately 3 days of high flows and one could focus on the cumulative 3-day flow for the evaluation. However, by evaluating the daily high flow events, we examine performance with respect to both magnitude and timing of the flow events. It is also noted that the response time of the Folsom Lake drainage is substantially less than $24 \mathrm{~h}$ so that the daily values in Fig. 10 represent mostly distinct flow events. Fig. 10 shows that in the Middle and South Fork most of the high flow simulations are conservative, i.e., simulation of the event magnitude is higher than that indicated by the observation. The results show less of a simulation bias for the North Fork high events. The Folsom Lake simulated inflow exhibits good agreement with the estimated FNF.

In Fig. 11 the observed and simulated daily hydrographs at the three forks, and the cumulative precipitation and snow water equivalent (SWE) measured by multiple snow pillows are displayed for the period December 1981-February 1982. The snow pillows (sensors) data were obtained from the California Data Exchange Center 〈www.cdec.ca.gov〉. During this period, two high flow events occurred following intense precipitation. The first event is largely driven by rain falling on essentially bare ground since the snow pack was not yet fully developed. This can be seen in the lower panels by comparing the cumulative precipitation to snow-pillow measurements in the basin. It is apparent that there is no reduction in the SWE at the time of the rain event, which occurred just before the first peak flow. In the second large event, runoff was generated from both rapid snow melt and rain on ground. This can be concluded by comparing the SWE and the precipitation events. It can be seen that the SWE at the North and Middle Forks is melting during the rain event. In the South Fork the sensor with the larger SWE content displays increase in SWE. The sensors with the middle SWE content display relatively little change, while the sensor with the lower SWE content shows depletion.

The observed SWE magnitudes in these plots are well correlated with the sensor elevation, i.e., the sensors that report higher SWE values are located in higher elevations. It can be inferred from the sensor data shown for the South Fork (lower right panel 

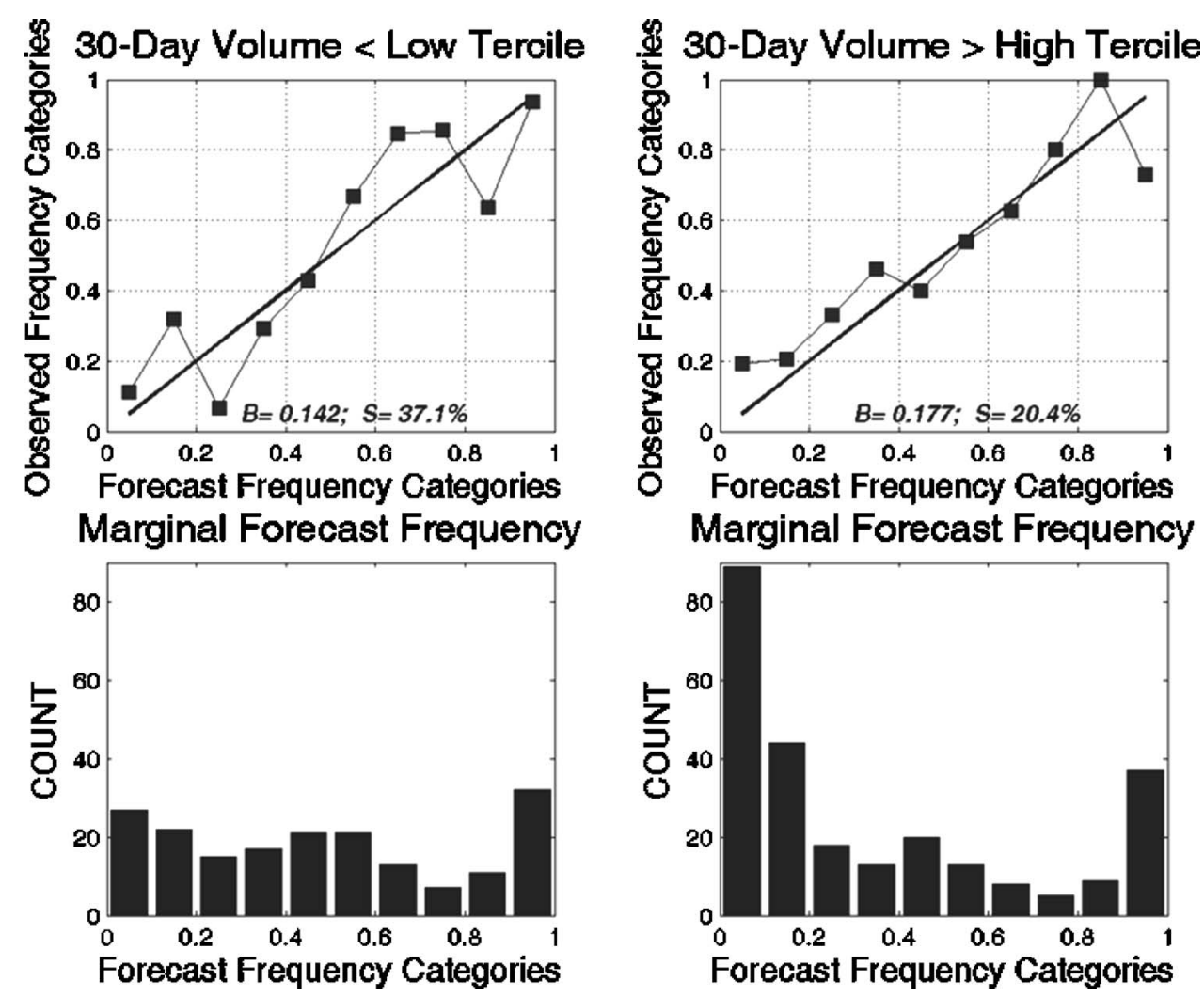

Fig. 12. Reliability diagrams (upper panels) and unconditional forecast frequency distributions (lower panels) for 30-day inflow volumes to Folsom Lake being in low tercile (left panels) and in high tercile (right panels) of their distribution. Line of perfect reliability and scalar Brier and Skill scores are also shown in upper panels. Stand alone hydrologic model ensemble forecasts were issued using NWS ESP on first day of each month for October 1958-September 1990

in Fig. 11) that during the precipitation event of the second hydrograph peak, the high elevation sensors show snow pack accumulation whereas the lower elevation sensor has a significant pack reduction that indicates rapid melt (rain on snow). The snow component of the operational hydrologic model allows for mixed snow/rain events over the basin. This is accomplished through area versus elevation relationships and a temperature lapse rate. However, the model does not perform a full spatially distributed volume accounting.

The hydrologic response and the basin depletion dynamics are captured in the simulations (e.g., the time of peak, recession shape, secondary peaks, etc.). However, as seen before, the simulation is consistently conservative in the Middle and South Forks. The model is overestimating both events in these forks, with an overestimation of almost $100 \%$ at the South Fork. The overestimation is pronounced in the second event which was a mix event of rain on ground and rain on snow. Although upstream regulation on the Middle and South Forks might affect even these high flows, the event magnitude points to model overestimation. However, Fig. 11 makes apparent that the hydrological model predicts well the peak flow of the North Fork. The conflicting results indicate that such events cannot be consistently treated by the current spatially lumped snow models, while a spatially distributed model could explicitly handle mixed precipitation events. Further discussion on the snow properties spatial variability and application of a distributed snow model in the American River basin is in Shamir and Georgakakos (2006).

\section{Ensemble Streamflow Predictions}

In this section we evaluate the performance of the ensemble streamflow prediction (ESP) procedure. Since historical ESP predictions are not currently archived operationally, they were recreated by a standalone version that uses the same model components (snow, soil, and channel models) as the operational version. The stand alone hydrologic model code was verified extensively to make sure that the operational forecast is reasonably well replicated. This model is used with the NWS ESP procedure (Day 1985) to develop retrospective ensemble flow forecasts with a 6-hourly resolution for the period 1958-1990. An ensemble of 30 members was generated once per month on the first day of the month with a maximum lead time of 90 days (360 6-h time steps).

The daily resolution ensemble flow forecast may be used to form a quantitative ensemble forecast of volume with duration from a day up to a maximum of 90 days. In the operational environment, the short time prediction is done by blending streamflow output forced by meteorological quantitative precipitation forecast (QPF) and temperature forecasts with ESP output generated from the observed mean areal precipitation and temperature. Here we aim to evaluate on a time scale in which ESP provides the only source of prediction. Of particular interest in large reservoir operations, when water conservation is a significant management objective, is water volume integrated over a number of days. We focus on the performance of the ensemble flow forecast 
system with respect to reproducing reliably the 30-day Folsom Lake inflow volumes.

A reliability diagram (Wilks 1995) is used as a performance measure of the forecasts (Fig. 12). This diagram displays the conditional probability of the observations given the forecasts for a range of forecasts frequencies (upper panels). The lower panels of Fig. 12 display the unconditional forecast frequencies. The evaluation was done on the capacity of the ensemble forecast to predict two events: volume in the lower tercile of its distribution (left panels) and volume in the upper tercile of its distribution (right panels). The terciles were determined from the distribution of the observed flow volumes.

Perfect reliability implies that, for all the dates that the forecast is in a certain frequency range, the actual observations produce the same frequency of occurrence when considered collectively. For example, if the ensemble produces a chance of the volume being in the lower tercile equal to $5 \%$ for each of 100 forecast times, a perfect reliability would require for the corresponding 100 observations that $5 \%$ of the events be within the lower tercile. In Fig. 12 perfect reliability points are located on the 1:1 line. We note that all the values were analyzed as anomalies to reduce seasonal dependencies. The transformation to a set of anomalies was done using

$$
X_{\text {anomalies }}=\left(X-\mu_{\text {monthly }}\right) / \sigma_{\text {monthly }}
$$

where $X=$ either simulated or observed values; and $\mu_{\text {monthly }}$ and $\sigma_{\text {monthly }}=$ long-term monthly mean and standard deviation, respectively, of specific months for the simulations or observations.

For most deciles and for both panels of Fig. 12, the reliability diagrams show good reliability and resolution; that is, forecasts were issued for each forecast range (see lower panels for distribution) and in most cases are close to the line of perfect reliability. Exceptions to this are forecasts issued for the forecast ranges $(0.2-0.3)$ and $(0.8-0.9)$ for the low tercile volume events and $(0.8-0.9)$ and $(0.9-1.0)$ of the high tercile volume events. It is also apparent that the low tercile volume forecasts have a more uniform distribution of forecasts across the different forecast ranges while the upper tercile volume forecasts appear sharper (i.e., high frequencies in very low and very high forecast ranges, resembling deterministic forecasts).

The scalar measures of performance, Brier and Skill score (e.g., Wilks 1995) were computed to provide summary performance statistics. The Brier score, denoted by $B$, is defined by

$$
B=N / \sum_{i=1}^{N}\left(f_{i}-o_{i}\right)^{2}
$$

where $N$ represents the total number of events of record for which a forecast frequency was computed from the ensemble forecasts; $f_{i}=$ forecast frequency for event $i$ (e.g., 30-day volume in the lower tercile of its distribution); and $o_{i}$ represents the observation of the event forecast that is 1 if the event occurs (i.e., the 30-day volume is indeed in the lower tercile of its distribution for the event $i$ ), and 0 if its does not occur. Perfect forecasts exhibit Brier scores equal to zero (0) while less accurate forecasts receive greater Brier scores. This score is bounded by 1 .

The Skill score, $S$, computed in this analysis and expressed as a percent is given by

$$
S=\left(1-B / B_{c}\right) \times 100
$$

where $B=$ Brier score computed from the ensemble model forecasts and $B_{c}=$ Brier score computed from a set of reference forecasts, which are the climatological relative frequencies of the tar- get inflow volume events in this case. Thus, the Skill score describes the percent improvement of the ESP in comparison to a forecast that is based on inflow volume climatology information.

The results of Fig. 12 indicate good Brier scores and substantial improvement with respect to forecasts that use climatological probabilities in both cases. The forecasts issued for low tercile inflow volume events do exhibit better scores, especially skill scores, indicating that the ensemble forecasts would be particularly useful for predicting drought periods and would likely contribute to better water conservation practices at Folsom Lake.

We close this section noting that in the Sierra Nevada there appears to have been a shift in the precipitation regime in the last 100 years (e.g., Cayan et al. 2001). Moreover, with the prospect of global warming and the effect that global events such as El Niño have on the Sierra Nevada, the ESP should be modified to account for these climatic effects. Carpenter and Georgakakos (2001) demonstrated the use of climate model output for the generation of conditioned ensemble streamflow predictions for the Folsom Lake drainage basin. Their results show improvement with respect to unconditioned ESP volume forecasts for high and low flow volumes.

\section{Conclusions and Recommendations}

For apparently the first time, a comprehensive evaluation of operational hydrologic models and forecasts for the Folsom Lake basin in California was conducted. Short term flow forecasts out to 5 days with 6-h resolution, 25-years retrospective model flow, and snow pack simulations with 6-h resolution, and retrospective ensemble streamflow predictions of monthly volumes were evaluated using operational quality observed data and a variety of performance criteria. Observations and simulations of the outflows of the North, Middle, and South Forks of the American River, and of the Full Natural Flow to the Folsom Lake were considered. The evaluation of the short-term forecasts was done for the period April 1998-January 2003 for which forecasts and observed data were available, whereas the retrospective deterministic and ensemble streamflow predictions used data that span the period from the late 1950s to the late 1980s. The data were made available by the California Nevada River Forecast Center of the U.S. National Weather Service.

The period of record that was available for the evaluation of the operational short term forecasts is characterized by relatively dry years with flow peaks up to $1,132 \mathrm{~m}^{3} / \mathrm{s}$. A set of the 25 more significant events among the record events was considered in the evaluation. The forecasts were produced in some cases using manual and/or automated state updating following operational procedures at the California Nevada River Forecast Center. The main conclusions from this evaluation are that: (1) the Middle and North Fork forecasts overestimate the observed 6-h flow by 10 $30 \%$, while the South Fork forecasts mean errors are less than $10 \%$ of the observed flow with a combined Fork flow overestimation of $10-20 \%$; (2) the forecasts generally explain a nonzero portion of the variance of the observations up until approximately $48 \mathrm{~h}$, beyond which the forecast error variance is equal to the observations variance; and (3) the correlation structure of the forecast errors of different lead times drops to values lower than about 0.6 for all forks and the combined flow for a lead time difference of $18 \mathrm{~h}$ (comparable to the basin response time for low flows), with the Middle and South Forks showing the sharpest and mildest drop in forecast error correlation. These results indicate that, for the low flow regime examined, the operational forecasts 
have significant skill in predicting the Fork outflows with lead times shorter than the basin response time, with a tendency to overestimate the event flows, especially in the North and Middle Forks.

Evaluation of the operational model simulations for the American River Forks and the Folsom Lake inflow indicates better performance in certain flow regimes. In light of the consistent biases encountered in all the evaluation points, it can be stated that the model calibration targeted the highest flow events. However, the very good performance of the model in the North Fork for a variety of performance criteria also means that the operational hydrologic model is describing the natural system well and has the capacity to reliably reproduce a variety of basin response properties. It is also clear that the operational forecasts evaluated for the North Fork suffer from the ill effects of significant errors in forecast precipitation and temperature used. The long-term differences found between the observations and the corresponding operational-model simulations are very likely due to the effect of upstream regulation impact on the natural flow of the Middle and South Forks.

Performance at the Middle and South Forks is decidedly worse than that of the North Fork. There were consistent biases in some of the flow magnitude regimes (e.g., consistent under estimation of the low flows in the Middle, South, and consistent over estimation of the medium to high magnitude at the Middle Fork). The simulations for these forks have also shown overestimation of the high flow events and deviations from seasonal and annual volume distributions. The above performance observations are mainly the effect of upstream regulation and water transfers between the basins that are not represented in the operational model simulations. In addition, it is shown that in cases when the precipitation across a fork basin is a mix of rain on ground and rain on snow, the current spatially-lumped operational model cannot consistently reproduce the flows well. In any case, the results show that the FNF into the Folsom Lake, which is a combination of the fork outflows and the Folsom local basin outflow, is simulated well by the operational model for the period of record except for a consistent underestimation of the low flows and annual volumes.

It is interesting to contrast the effect of upstream flow regulations on the performance of the short term forecasts and long term model simulations. For the former, upstream flow regulation decreases the variability in the flow. Moreover, the professional forecasters that issue the short term forecasts are usually familiar with local operational practices. Thus, upstream streamflow regulation improves the short term forecast skill. On the contrary, for long term simulations in which the model parameters and structure are static and set to represent the natural system, upstream regulation cannot be reproduced reliably by the simulations and therefore consistently deteriorate model performance with time.

Evaluation of the ensemble monthly flow volume predictions of the operational hydrologic model using reliability diagrams and the Brier Score reveals that the ensemble predictions generally have good reliability and resolution in predicting both high and low monthly volume extremes (upper and lower terciles). In both cases of high and low monthly volumes, high confidence probabilistic predictions tend to deviate from the corresponding observed frequency, with most of the probabilistic forecasts contained within the high and low deciles of the (0-1) range. The scalar Brier and Skill scores indicate substantial skill for both high and low monthly volume tercile targets, with the ensemble predictions being significantly better than climatology, especially for the low monthly volume target. These results encourage the use of operational ensemble streamflow predictions of monthly volumes for water resources applications.

These findings of the evaluation research lead to several recommendations for further research and development. The most restrictive aspect of the research reported was the lack of archives of operational flow forecasts that span a long historical period. Perhaps our most important recommendation is the establishment of a national operational archive of short and long term model and human-forecaster-modified flow forecasts and associated flow observations for the periodic objective evaluation of the forecasts in various areas of the United States. This will generate the basis for future model and forecast improvements, for the evaluation of forecast performance trends, for future relevant research, and for the development of objective guidelines for the use of the forecasts by the public and by water managers.

An important next step in terms of model improvement for the Folsom Lake basin is the incorporation of upstream regulations in some fashion into the model structure. As evident from the evaluation of operational flow forecasts, real time adjustments reduce the impact of the short term upstream regulation on the forecast quality. However, a more direct approach is necessary for longterm predictions. Although some of the operational decisions associated with the regulation of upstream reservoirs are difficult to predict, a first approach may be to identify the basic patterns of the regulation with respect to streamflow and meteorological conditions. The adequacy of such an approach is conditioned on the ability to associate the regulation patterns to readily available data (e.g., precipitation and temperature) or to the real time availability of release outflow from upstream storage facilities.

Other improvements of the model pertain to the summer time simulation errors and to the snow model uncertainties. Refinement of the parameter values of the lower zone in the Sacramento model as regards their influence on the accuracy of low flow volume simulation, should improve model summer behavior. With respect to the snow model, understanding the uncertainty associated with the use of a spatially lumped model by comparing performance to that of a spatially distributed model for a variety of snow accumulation and ablation events should lead to guidelines for improving model structure and parameters for the application basin. In that case, of course, uncertainties in reproducing the spatially distributed basin precipitation and temperature must be taken into consideration.

The reliable results produced by the ensemble streamflow procedure indicate that such predictions may be useful for managing the water resources of Folsom Lake in an operational environment. Studies along those lines should continue emphasizing the attributes of the ensemble streamflow predictions most useful for the operational management of the Folsom reservoir. In addition, conditioning the ensemble streamflow predictions with climate information should further improve longer lead time ensemble predictions. Finally, real time experiments of utilizing ensemble forecasts for reservoir management would also provide a solid basis for the operational use of integrated forecast-management systems.

\section{Acknowledgments}

The writers gratefully acknowledge the many and varied contributions of CNRFC personnel, and especially Eric Strem, and Robert Hartman, in making data available and in providing comments and reviews of our results and of early versions of this paper. They also thank three anonymous reviewers for their con- 
tribution toward improving the clarity of the original manuscript. The research was sponsored by the Ecosystem Restoration California Bay Delta Authority (Award No. ERP-02-P13), the NOAA Office of Global Programs (Award No. NA16GP2711), and by the PIER Program of the California Energy Commission (Award No. 500-02-008) as part of the Integrated Forecast and Reservoir Management (INFORM) Project. Additional support was provided by the USA Corps of Engineers, Sacramento District, under Award No. DACW05-02-P-0183. The opinions expressed herein are those of the writers and do not necessarily reflect those of the sponsoring Agencies and their subagencies.

\section{References}

Anderson, E. A. (1973). "National Weather Service river forecast system-Snow accumulation and ablation model." NOAA Technical Memorandum NWS HYDRO-17, Office of Hydrology, National Weather Service, NOAA, Silver Spring, Md.

Berri, G. J., and Flamenco, E. A. (1999). "Seasonal volume forecast of the Diamante River, Argentina, based on El Niño observations and predictions." Water Resour. Res., 35(12), 3803-3810.

Box, G. E. P., and Cox, O. R. (1964). "The analysis of transformation." J. R. Stat. Soc. Ser. B. Methodol., 26(2), 211-252.

Bradley, A. A., Schwartz, S. S., and Hashino, T. (2004). "Distributedoriented verification of ensemble streamflow predictions." J. Hydrometeor, 5(3), 532-545.

Burnash, R. J. C., Ferral, R. L., and McGuire, R. A. (1973). “A generalized streamflow simulation system: conceptual modeling for digital computers." US National Weather Service and California Department of Water Resources Rep., Joint Federal State River Forecast Center, Sacramento, Calif.

Carpenter, T. M., and Georgakakos, K. P. (2001). “Assessment of Folsom Lake response to historical and potential future climate scenarios: 1 . Forecasting." J. Hydrol., 249(1), 148-175.

Case, J. L., Manobianco, J., Dianic, A. V., Wheeler, M. M., Harms, E., and Parks, C. R. (2002). "Verification of high-resolution RAMS forecasts over east-central Florida during the 1999 and 2000 summer months." Weather Forecast., 17(6), 1133-1151.

Cayan, D. R., Kammerdiener, S. A., Dettinger, M. D., Caprio, J. M., and Peterson, D. H. (2001). "Changes in the onset of spring in the Western United States.” Bull. Am. Meteorol. Soc., 82(3), 399-413.

Day, G. N. (1985). "Extended Streamflow forecasting using the NWSRFS." J. Water Resour. Plan. Manage., 111(2), 3157-170.

Franz, K. J., Hartmann, H. C., Sorooshian, S., and Bales, R. (2003). "Verification of National Weather Service ensemble streamflow predictions for water supply forecasting in the Colorado River Basin." J. Hydrometeor, 4(6), 1105-1118.

Gentry, R. C. (1950). "Forecasting local showers in Florida during the summer." Mon. Weather Rev., 78(3), 41-49.

Georgakakos, A. P., Mullusky, M. G., and Georgakakos, K. P. (1998). "Impacts of climate variability on the operational forecast and management of the upper Des Moines River basin." Water Resour. Res., 34(4), 799-821.

Georgakakos, K. P. (1986). "A generalized stochastic hydrometeorological model for flood and flash flood forecasting, 1: Formulation." Water Resour. Res., 22(13), 2083-2095.

Georgakakos, K. P., and Bras, R. L. (1982). "Real-time, StatisticallyLinearized, Adaptive Flood Routing." Water Resour. Res., 18(3), 513-524.

Hartmann, H. C., Pagano, T. C., Bales, R., and Sorooshian, S. (2002). "Confidence builders: evaluating seasonal climate forecasts from user perspectives.” Bull. Am. Meteorol. Soc., 83(5), 683-698.

Koren, V., Smith, M., Wang, D., and Zhang, Z. (2000). "Use of soil property in the derivation of conceptual rainfall-runoff model parameters." Proc., Preprints 80th Annual Meeting of the AMS, Long Beach, Calif., American Meteorological Society, Boston.
Lettenmaier, D. P., and Gan, T. Y. (1990). "Hydrologic sensitivities of the Sacramento-San Joaquin River Basin, California, to global warming." Water Resour. Res., 26(1), 69-86.

Li, P. W., and Lai, E. S. T. (2004). "Short-range quantitative precipitation forecasting in Hong Kong." J. Hydrol., 288(1), 189-209.

Lohmann, D., et al. (2004). "Streamflow and water balance intercomparisons of four land-surface models in the North American Land Data Assimilation System project.” J. Geophys. Res., 109(D7), D07S91.

Manning, K. W., and Davis, C. A. (1997). "Verification and sensitivity experiments for the WISP94 MM5 forecasts." Weather Forecast., 12(4), 719-735.

McBride, J. L., and Ebert, E. E. (2000). "Verification of quantitative precipitation forecasts from operational numerical weather prediction models over Australia." Weather Forecast., 15(1), 103-121.

Mullen, S. L., and Buizza, R. (2001). "Quantitative precipitation forecasts over the United States by the ECMWF ensemble prediction system." Mon. Weather Rev., 129(4), 638-663.

Murphy, A. H., and Winkler, R. L. (1987). “A general framework for forecast verification.” Mon. Weather Rev., 115(7), 1330-1338.

National Research Council (NRC). (1995). Flood risk management and the American River basin, an evaluation, National Academy Press, Washington, D.C.

National Weather Service (NWS). (1999a). National Weather Service river forecast system (NWSRFS) user manual. NOAA-National Weather Service, Office of Hydrologic Development, Silver Spring, Md.

National Weather Service (NWS). (1999b). "Sacramento soil-moisture accounting model calibration, demonstration of the interactive approach." NOAA VHS Training Video Series Produced by HRC, Office of Hydrologic Development, Silver Spring, Md.

Nutter, P. A., and Manobianco, J. (1999). "Evaluation of the 29-km Eta model. Part I: Objective verification at three selected stations." Weather Forecast., 14(1), 5-17.

Olson, D. A., Junker, N. W., and Korty, B. (1995). "Evaluation of 33 years of quantitative precipitation forecasting at the NMC." Weather Forecast., 10(3), 498-511.

Oreskes, N., Schrader-Frechette, K., and Blittz, K. (1994). "Verification, validation and confirmation of numerical models in the earth science." Science, 263(5147), 641-646.

Piechota, T. C., Chiew, F. H. S., Dracup, J. A., and McMahon, T. A. (1998). "Seasonal streamflow forecasting in eastern Australia and the El Niño-Southern Oscillation." Water Resour. Res., 34(11), 3035-3044.

Refsgaard, J. C., and Knudsen, J. (1996). "Operational validation and intercomparison of different types of hydrological models." Water Resour. Res., 32(7), 2189-2202.

Şen, Z., Altunkaynak, A., and Özger, M. (2003). “Autorun persistence of hydrologic design.” J. Hydrologic Eng., 8(6), 329-338.

Shamir, E., and Georgakakos, P. K. (2006). "Distributed snow accumulation and ablation modeling in the American River basin." Adv. Water Resour., 29(4), 558-570.

Shamir, E., Imam, B., Gupta, H. V., and Sorooshian, S. (2005). "Application of temporal streamflow descriptors in hydrologic model parameter estimation." Water Resour. Res., 41(6), W06021.

Smith, J. A., Day, G. N., and Kane, M. D. (1991). "A non parametric framework for long-range streamflow forecasting." WMO/TD-428, World Meteorological Organization, Geneva, Switzerland.

Smith, M. B., Laurine, D. P., Koren, V. I., Reed, S. M., and Zhang, Z. (2003). "Hydrologic model calibration in the National Weather Service." American Geophysical Union Monograph: Advances in model calibration, Q. H. Duan H. V. Gupta, S. Sorooshian, A. N. Rousseau, and R. Turcotte, eds., American Geophysical Union, Washington, D.C., 133-152.

Smith, M. B., et al. (2004). "The distributed model intercomparison project (DMIP): Motivation and experiment design." J. Hydrol., 298(1), 4-26.

Sokol, Z. (2003). "MOS-Based Precipitation Forecasts for River Basins." Weather Forecast., 18(5), 769-781. 
Sorooshian, S., and Dracup, J. A. (1980). "Stochastic parameter estimation procedures for hydrologic rainfall-runoff models: Correlated and heteroscedastic error cases." Water Resour. Res., 16(2), 430-442.

Sperfslage, J. A., and Georgakakos, K. P. (1996). "Implementation and testing of the HFS operation as part of the National Weather Service river forecast system." HRC TR 1, Hydrologic Research Center, San Diego.

Tsintikidis, D., Georgakakos, K. P., Sperfslage, J. A., Smith, D. E., and Carpenter, T. M. (2002). "Precipitation uncertainty and raingauge network design within Folsom Lake watershed." J. Hydrologic Eng., $7(2), 175-184$.

Uvo, C. B., and Graham, N. E. (1998). "Seasonal runoff forecast for northern South America: A statistical model." Water Resour. Res., 34(12), 3515-3524.

Wilks, D. S. (1995). Statistical methods in the atmospheric sciences, Academic, New York.

Wilks, D. S. (2000). "Diagnostic verification of the climate prediction center long-lead outlooks, 1995-98." J. Clim., 13(13), 2389-2403.
World Meteorological Organization (WMO). (1975). "Intercomparison of conceptual models used in operational hydrologic forecasting." Operational Hydrology Rep. No. 7, Geneva.

World Meteorological Organization (WMO). (1986). "Intercomparison of models of snowmelt runoff." Operational Hydrology Rep. No. 23, Geneva.

World Meteorological Organization (WMO). (1992). "Simulated real time intercomparison of hydrological models." WMO Operational Hydrology Rep. No. 38, Geneva.

Xia, Y., Yang, Z. L., Jackson, C., Stoffa, P. L., and Sen, M. K. (2004). "Impacts of data length on optimal parameter and uncertainty estimation of a land surface model." J. Geophys. Res., 109, D07101.

Yao, H., and Georgakakos, A. P. (2001). "Assessment of Folsom Lake response to historical and potential future scenarios: 2. Reservoir management." J. Hydrol., 249(1), 176-196.

Yapo, P., Gupta, H. V., and Sorooshian, S. (1996). "Calibration of conceptual rainfall-runoff models: Sensitivity to calibration data." J. Hydrol., 181(1), 23-48. 